\title{
Design of an improved universal signal peptide based on the a-factor mating secretion signal for enzyme production in yeast
}

\author{
Pablo Aza ${ }^{1}$ (D) Gonzalo Molpeceres $^{1}$ (D) $\cdot$ Felipe de Salas $^{1}$ (D) $\cdot$ Susana Camarero ${ }^{1}$ (D)
}

Received: 7 October 2020 / Revised: 10 February 2021 / Accepted: 18 February 2021 / Published online: 9 March 2021

(c) The Author(s) 2021

\begin{abstract}
Saccharomyces cerevisiae plays an important role in the heterologous expression of an array of proteins due to its easy manipulation, low requirements and ability for protein post-translational modifications. The implementation of the preproleader secretion signal of the $\alpha$-factor mating pheromone from this yeast contributes to increase the production yields by targeting the foreign protein to the extracellular environment. The use of this signal peptide combined with enzyme-directed evolution allowed us to achieve the otherwise difficult functional expression of fungal laccases in S. cerevisiae, obtaining different evolved $\alpha$-factor preproleader sequences that enhance laccase secretion. However, the design of a universal signal peptide to enhance the production of heterologous proteins in S. cerevisiae is a pending challenge. We describe here the optimisation of the $\alpha$-factor preproleader to improve recombinant enzyme production in S. cerevisiae through two parallel engineering strategies: a bottom-up design over the native $\alpha$-factor preproleader $\left(\alpha_{\text {nat }}\right)$ and a top-down design over the fittest evolved signal peptide obtained in our lab ( $\alpha_{9 \mathrm{H} 2}$ leader). The goal was to analyse the effect of mutations accumulated in the signal sequence throughout iterations of directed evolution, or of other reported mutations, and their possible epistatic interactions. Both approaches agreed in the positive synergism of four mutations (A $\alpha 9 \mathrm{D}, \mathrm{A} \alpha 20 \mathrm{~T}, \mathrm{~L} \alpha 42 \mathrm{~S}, \mathrm{D} \alpha 83 \mathrm{E})$ contained in the final optimised leader $\left(\alpha_{\mathrm{OPT}}\right)$, which notably enhanced the secretion of several fungal oxidoreductases and hydrolases. Additionally, we suggest a guideline to further drive the heterologous production of a particular enzyme based on combinatorial saturation mutagenesis of positions 86 th and 87 th of the $\alpha_{\mathrm{OPT}}$ leader fused to the target protein.
\end{abstract}

Keywords Signal peptide $\cdot$ Synthetic design $\cdot$ Enzyme heterologous expression $\cdot$ A-factor preproleader $\cdot$ Saccharomyces cerevisiae $\cdot$ Directed evolution

\section{Introduction}

Enzyme heterologous expression has been a target of interest in protein research for the last decades. Historically, the yeast Saccharomyces cerevisiae has served as an expression system for eukaryotic proteins since it meets the essential protein post-translational demands, such as formation of disulfide bonds or glycosylation $[1,2]$ and, besides, its simple growth requirements, low average production time and well-known genome facilitate its manipulation [3, 4]. From

Pablo Aza and Gonzalo Molpeceres are contributed equally to this manuscript.

Susana Camarero

susanacam@cib.csic.es

1 Centro de Investigaciones Biológicas Margarita Salas, CSIC, Ramiro de Maeztu 9, 28040 Madrid, Spain and industrial point of view, S. cerevisiae is still extensively used for obtaining therapeutic proteins [5] and pharmaceuticals products approved for human use by the Food and Drug Administration (FDA) [6]. However, very often, the protein yields provided by this yeast is barely sufficient for research and certainly not suitable for commercialization [7, 8]. The use of yeast signal peptides has been one of the most successful strategies utilized so far to enhance secretion of recombinant enzymes, since signal peptides determine the secretion pathway of the proteins and traffic them to their final site of action $[9,10]$. Among them, the leader sequence of the $\alpha$-factor mating pheromone of $S$. cerevisiae (MF 1 ) has played an important role in the production of recombinant proteins from different sources in yeast [11-14].

MF $\alpha 1$ gene structure consists of a signal sequence, known as $\alpha$-factor preproleader, fused to four copies of the 13-residue $\alpha$-factor protein, each of them preceded by a spacer peptide of 6-8 amino acids [Lys-Arg-(Glu/Asp-Ala) $)_{2-3}$ ] 


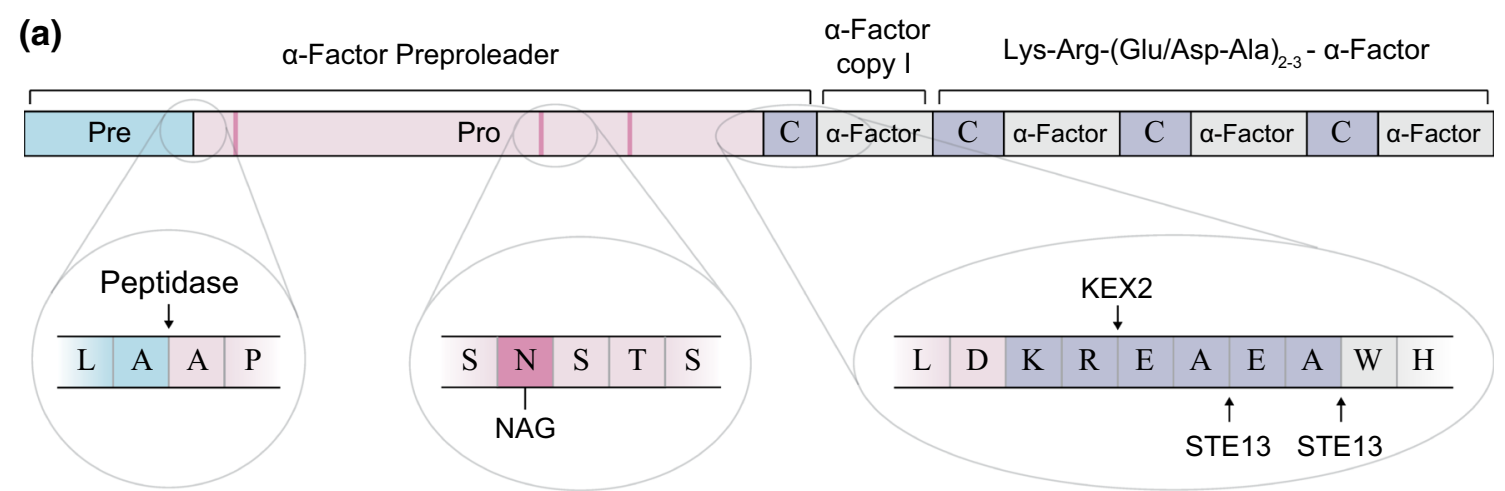

(b)

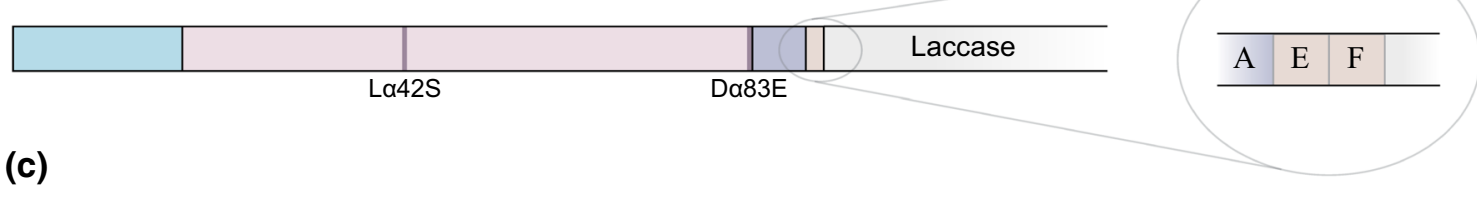

(c)

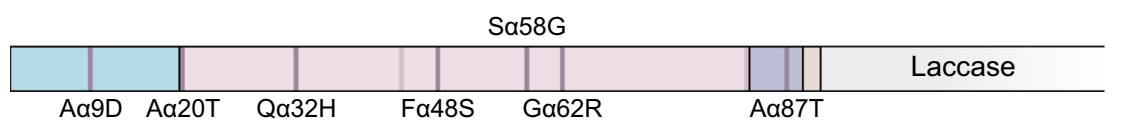

Fig. 1 Scheme of MF $\alpha 1$ gene from $S$. cerevisiae and signal peptides. a The $\alpha$-factor preproleader consists of a pre-region, a pro-region (with three $N$-glycosylation sites) and the first spacer (with KEX2 and STE13 cleavage sites). The signal peptide is followed by four $\alpha$-factor gene copies separated by spacers (C) of different length. b The $\alpha_{\text {nat }}$ leader used in this study containing L $\alpha 42 \mathrm{~S}$ and D $\alpha 83 \mathrm{E}$ muta-

(Fig. 1a) [15-17]. By contrast to short canonical signal peptides (20-30 aa) [10], the $\alpha$-factor preproleader comprises a long sequence of 89 amino acids divided into three structural parts: a 19-residue pre-region, a 64-residue proregion and the first spacer of 6 amino acid residues. The pre-region displays a typical signal peptide structure with the following common motifs: a $\mathrm{N}$-terminal positive charged domain, an hydrophobic core, and a final polar C-terminal end followed by the 64 residues of the pro-region. The latter and the spacer drive the final processing and release the $\alpha$-factor mating pheromone to the extracellular media [16-18]. Moreover, the pro-region has three $N$-glycosylation sites that, although not being essential for secretion, appear to facilitate the transport from Endoplasmic Reticulum (ER) to Golgi apparatus [19, 20].

During their processing in S. cerevisiae, proteins directed by the $\alpha$-factor preproleader are believed to be translocated across the ER membrane to the lumen in a post-translational pathway $[21,22]$. Then, the pre-region is cleaved by an undetermined signal peptidase between the 19th and 20th positions [17, 23, 24], and the addition of $N$-linked glycosylation in the pro-region occurs [19]. At this point, the pro-protein is driven to its final post-translational processing at Golgi apparatus [25, 26]. Once there, KEX2 tions from pPICZ $\alpha$ (Invitrogen) and the extra Glu-Phe residues after the spacer (light orange). c Evolved $\alpha_{9 \mathrm{H} 2}$ leader with A $\alpha 9 \mathrm{D}, \mathrm{A} \alpha 20 \mathrm{~T}$, $\mathrm{Q} \alpha 32 \mathrm{H}, \mathrm{F} \alpha 48 \mathrm{~S}, \mathrm{~S} \alpha 58 \mathrm{G}, \mathrm{G} \alpha 62 \mathrm{R}, \mathrm{A} \alpha 87 \mathrm{~T}$ mutations (dark purple), as well as L $\alpha 42 \mathrm{~S}, \mathrm{D} \alpha 83 \mathrm{E}$ mutations (light purple) and extra Glu-Phe (light orange)

protease processes the peptide behind the dibasic sequence Lys84-Arg85 [17, 27], remaining four extra amino acids at the $\mathrm{N}$-terminus of the protein. After their final cleavage by the action of the STE13 protease, the mature protein form is released to the culture media [28]. Although the yeast can manage the secretion of enzyme with the pre-region alone, the pro-region is important to facilitate the secretion [29]. It is generally assumed that the pro-region provides a proper transit of nascent peptides from ER lumen to Golgi apparatus in a COPII dependent pathway [22, 25, 26, 30, 31]. However, some studies point its role at protein translocation to the ER lumen $[12,13]$.

The versatility of the $\alpha$-factor preproleader has been utilised for functional expression in yeast of a wide range of proteins such as fungal proteins [12,32-34], green fluorescence proteins (GFPs) [13] or vaccines and pharmaceutical products (e. g. human insulin) [14]. One step further is the engineering of the signal peptide to raise the protein levels. Random mutagenesis of the $\alpha$-factor preproleader improved Interleukin secretion more than twofold and highlighted the importance of increased hydrophobicity from 63rd to 66th positions of the pro-region [20]. In this work line, mutations accumulated in the $\alpha$-factor preproleader during the directed evolution of fungal laccases fused 
to this signal sequence improved laccase secretion levels up to 40-fold [32] while demonstrated the crucial role of mutations at the pre-region for enzyme secretion [32,33]. Other rational studies revealed the importance of single mutations such as L $\alpha 42 S$ [35] or the role of specific motifs in the pro-region [25].

Laccases (EC 1.10.3.2) are multicopper oxidases able to oxidize phenols, aromatic amines, $\mathrm{N}$-heterocycles, thiols and some metals. In fungi, they play a crucial role in wood delignification, and are involved in other processes such as detoxification, morphogenesis, pathogenesis and response to stress [36, 37]. Four copper ions participate in the catalysis; the monovalent oxidation of the substrate occurs at the T1 copper site; then, four electrons are transferred to the trinuclear cluster, formed by one $\mathrm{T} 2$ and two T3 copper ions, where oxygen is reduced to water [38,39]. The high redox potential at $\mathrm{T} 1$ copper of certain basidiomycete laccases (around $+800 \mathrm{mV}$ ), high stability and substrate versatility, together with the use of oxygen from the air as sole requirement and the release of water as only by-product, make them green biocatalysts of choice for different industrial sectors [40]. Nevertheless, most wild basidiomycete strains produce low laccase levels and laccase heterologous expression is difficult, being a suitable target for directed evolution [32, $33,41]$.

Several mutated $\alpha$-factor preproleader sequences with improved secretory properties have been reported so far [20, 32-35, 42]. In particular, the co-evolution of this signal peptide fused to different fungal laccases during enzymedirected evolution campaigns carried out in $S$. cerevisiae successfully enhanced laccase secretion [32, 33, 42-44]. However, designing an improved "universal" signal peptide capable of enhancing yeast production of a variety of different enzymes remains as a challenging task. We describe here a dual engineering approach of the $\alpha$-factor preproleader to increase its ability to secrete recombinant enzymes and to add insights into its structure. We conducted a bottom-up optimisation design based on the mutations accumulated in $\alpha_{9 \mathrm{H} 2}$, a recently evolved $\alpha$-factor preproleader that contributes to the highest yields reported so far for a basidiomycete laccase produced in S. cerevisiae [42], and on other mutations selected in previous directed evolution campaigns, to study their influence alone as well as the interactions between them. In parallel, a top-down design served us to eliminate possible deleterious mutations accumulated in $\alpha_{9 \mathrm{H} 2}$ leader. The secretory potentials of the $\alpha$-factor leader sequences derived from both pathways were tested with two fungal laccases sharing $~ 60 \%$ sequence identity: the engineered PK2 laccase (Polyporales origin), obtained in the same evolution campaign than $\alpha_{9 \mathrm{H} 2}$ [42], and a laccase synthesised de novo from the Agaricales fungus Agrocybe pediades (ApL, unpublished data). The optimised signal peptide was subsequently evaluated with other fungal oxidoreductases and hydrolases to asses its ability as an allpurpose leader to improve the secretion of different types of enzymes by the yeast.

\section{Results}

In a previous work, we proved the capability of the evolved $\alpha_{9 \mathrm{H} 2}$ leader [42] to improve the secretion by $S$. cerevisiae of diverse laccases compared to other evolved signal peptides [46]. The $\alpha_{9 \mathrm{H} 2}$ leader differs from the native $\alpha$-factor preproleader, $\alpha_{\text {nat }}$ leader from now on (Fig. 1b, Fig S1), in seven mutations (Fig. 1c) accumulated through subsequent evolution campaigns. Mutations A $\alpha 9 \mathrm{D}, \mathrm{F} \alpha 48 \mathrm{~S}, \mathrm{~S} \alpha 58 \mathrm{G}$, Ga62R were added during the directed evolution of Pycnoporus cinnabarinus laccase ( $\mathrm{PcL}$ ) for functional expression in S. cerevisiae [32], and A $\alpha 87$ T during the evolution of PM1 laccase (PM1L [33]); all accumulated in the leader sequence of 7D5 chimeric laccase after DNA shuffling of evolved PcL and PM1L [44]. The A $\alpha 20 \mathrm{~T}$ and Q $\alpha 32 \mathrm{H}$ mutations were selected during subsequent evolution of 7D5 laccase to obtain PK2 variant [42]. It is worth noting that $\alpha_{\text {nat }}$ and $\alpha_{9 \mathrm{H} 2}$ leaders contain 2 extra mutations (L $\alpha 42 \mathrm{~S}$ and $\mathrm{D} \alpha 83 \mathrm{E}$ ) with respect to the original $\mathrm{MF} \alpha 1$ gene [18]. Both mutations come from the $\alpha$-factor preproleader of Invitrogen (inserted in pPICZ $\alpha$ plasmids [35]). In addition, the $\alpha_{\text {nat }}$ leader we used here holds a EcoRI restriction site that was introduced to facilitate genetic engineering and encodes for a Glu-Phe extra sequence downstream the spacer and before the foreign protein (Fig. 1b, c).

First, the secretory potentials of the $\alpha_{9 \mathrm{H} 2}$ leader was compared with the $\alpha_{\text {nat }}$ leader for laccase production. Both signal sequences, fused to the CDS of PK2 and ApL laccases were cloned in the pJRoC30 expression vector to transform $S$. cerevisiae cells. Yeast clones were grown in 96-well plates in SEM laccase expression medium [45] and the secreted activity was determined by the oxidation of ABTS (absorbance peak at $418 \mathrm{~nm}$ ). While both construction gave detectable laccase activity, $\alpha_{9 \mathrm{H} 2}$ leader provided significantly higher laccase activity levels than $\alpha_{\text {nat }}$ leader, roughly twofold for PK2 and 12-fold for ApL (Fig. S2), confirming previous results obtained with ApL [46]. Due the superiority of $\alpha_{9 \mathrm{H} 2}$, it was used as upper reference leader in this study. Two engineering strategies were carried out: (i) a bottom-up process over $\alpha_{\text {nat }}$ to study the individual effect of mutations accumulated in $\alpha_{9 \mathrm{H}_{2}}$ and others, and their epistatic interactions, and (ii) a top-down process over $\alpha_{9 \mathrm{H} 2}$ to get rid of possible deleterious mutations accumulated during the in vitro evolution pathway that could mask the effect of real beneficial mutations. 


\section{Bottom-up design of $a_{\text {nat }}$ leader}

Site-directed mutagenesis on $\alpha_{\text {nat }}$ leader was performed to independently assess the effect of the following mutations: (i) the seven mutations accumulated in $\alpha_{9 \mathrm{H} 2}$ leader (A $\alpha 9 \mathrm{D}, \mathrm{A} \alpha 20 \mathrm{~T}, \mathrm{Q} \alpha 32 \mathrm{H}, \mathrm{F} \alpha 48 \mathrm{~S}, \mathrm{~S} \alpha 58 \mathrm{G}, \mathrm{G} \alpha 62 \mathrm{R}, \mathrm{A} \alpha 87 \mathrm{~T}$ ) that were individually added to $\alpha_{\text {nat }}$ leader, (ii) the two mutations found in $\alpha_{\text {nat }}$ from pPICZ $\alpha$ plasmid (L $\alpha 42 \mathrm{~S}$, $\mathrm{D} \alpha 83 \mathrm{E}$ ) that were removed individually, and (iii) four potentially beneficial mutations ( $\alpha \alpha 2 S, T \alpha 24 S, L \alpha 44$ S and E $\alpha 86 \mathrm{G})$ selected in previous studies $[32,33$ ] that were added individually to $\alpha_{\text {nat }}$ leader. The resulting 13 singlemutated $\alpha_{\text {nat }}$ leaders were fused to each laccase CDS (PK2 and $\mathrm{ApL}$ ), cloned and expressed in S. cerevisiae. Laccase activities secreted by ten replicates of each clone grown in 96-well plates were screened with ABTS as substrate. The average laccase activity of each single mutant was normalized to the parental activity (with $\alpha_{\text {nat }}$ leader), and similarities and differences in secretion were statistically supported by the Tukey's range test. Satisfactorily, most of the mutations showed the same behaviour for the production of both laccases (Fig. 2). Clearly beneficial mutations were localised in the pre-region or near it; R $\alpha 2 \mathrm{~S}, \mathrm{~A} \alpha 9 \mathrm{D}$ and $A \alpha 20 \mathrm{~T}$ augmented around twofold the secretion of both laccases, whereas T $\alpha 24 \mathrm{~S}$ mutation improved their secretion dissimilarly (1.3-fold for PK2 and threefold for ApL). On the other hand, Q $\alpha 32 \mathrm{H}, \mathrm{L} \alpha 44 \mathrm{~S}, \mathrm{~F} \alpha 48 \mathrm{~S}, \mathrm{~S} \alpha 58 \mathrm{G}$ had no effect on the secretion of PK2 and ApL, while Go62R mutation had a detrimental effect on PK2 secretion

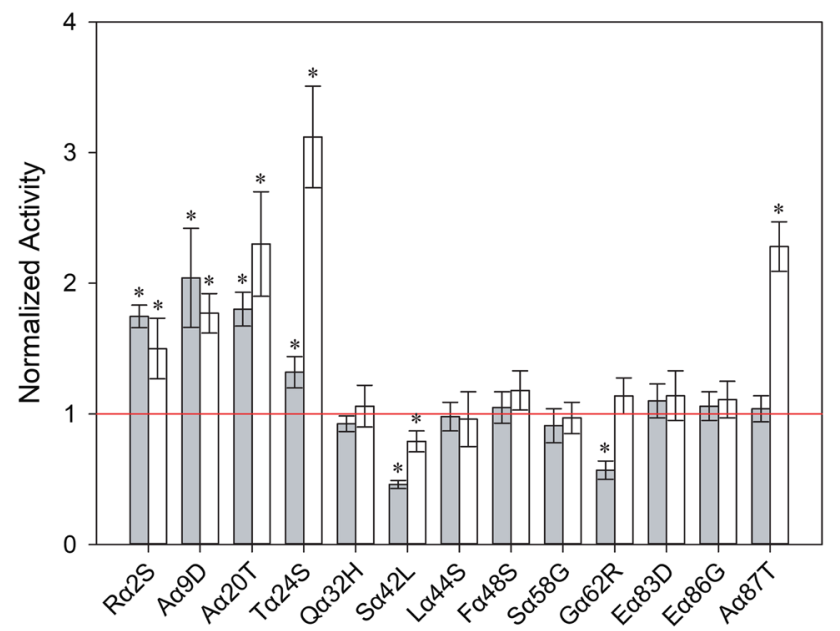

Fig. 2 Laccase activities detected in S. cerevisiae microcultures expressing either PK2 (grey bars) or ApL (white bars) fused to the different single-mutated $\alpha$ leaders. Laccase activities were normalized to that of the corresponding parent type $\alpha_{\text {nat }}-\mathrm{PK} 2$ or $\alpha_{\text {nat }}-\mathrm{ApL}$ (red line). Error bars correspond to the error propagation of ten replicates of each parent type or individual mutant. Asterisks highlight significant differences between individual mutants and parent types according to Tukey's range test (95\% confidence) (0.57-fold) and neutral effect on ApL. Mutations located in the spacer region had different effects: E $\alpha 86 \mathrm{G}$ seemed to have no influence on laccase secretion, while A $\alpha 87 \mathrm{~T}$ highly improved the activity levels of ApL (2.3-fold) but not of PK2. Removal of L $\alpha 42 S$ mutation decreased laccase secretion to 0.8-fold (ApL) and 0.4-fold (PK2) the activities detected with $\alpha_{\text {nat }}$ leader. Reversion of $\mathrm{D} \alpha 83 \mathrm{E}$ had no effect. Nevertheless, both mutations, beneficial L $\alpha 42 \mathrm{~S}$ and neutral D $\alpha 83 \mathrm{E}$, were maintained in next assays because they were originally present in $\alpha_{\text {nat }}$ leader from Invitrogen and every substitution selected during the evolution to $\alpha_{9 \mathrm{H} 2}$ leader could have had epistatic interactions with them.

Next, we analysed the potential synergism between beneficial mutations R $\alpha 2 \mathrm{~S}, \mathrm{~A} \alpha 9 \mathrm{D}, \mathrm{A} \alpha 20 \mathrm{~T}$ and T $\alpha 24 \mathrm{~S}$. Based on a proximity criteria, double $\left(\alpha_{\mathrm{R} 2 \mathrm{~S}, \mathrm{~A} 9 \mathrm{D}}\right.$ and $\left.\alpha_{\mathrm{A} 20 \mathrm{~T}, \mathrm{~T} 24 \mathrm{~S}}\right)$ and quadruple $\left(\alpha_{\mathrm{R} 2 \mathrm{~S}, \mathrm{~A} 9 \mathrm{D}, \mathrm{A} 20 \mathrm{~T}, \mathrm{~T} 24 \mathrm{~S}}\right)$ mutants of $\alpha_{\text {nat }}$ leader were obtained and fused to ApL and PK2 laccases. In addition, we built a double mutant $\left(\alpha_{\mathrm{E} 86 \mathrm{G}, \mathrm{A} 87 \mathrm{~T}}\right)$ at the spacer region. Again, ten replicates of each $S$. cerevisiae clone expressing the aforementioned constructions were grown in 96-well plates; the activities of the supernatants were measured and the corresponding average activities normalized to the laccase activity obtained with the $\alpha_{\text {nat }}$ leader (Fig. 3a, b). All data were supported by Tukey's range test. The $\alpha_{\mathrm{R} 2 \mathrm{~S}, \mathrm{~A} 9 \mathrm{D}}$ leader diminished laccase secretion with respect to $\alpha_{\text {nat }}$ leader (to 0.2-fold for PK2 and 0.9-fold for ApL). The $\alpha_{\mathrm{A} 20 \mathrm{~T}, \mathrm{~T} 24 \mathrm{~S}}$ leader favoured ApL secretion as compared to $\alpha_{\text {nat }}$ leader (1.4-fold), but the combination of both mutations was detrimental compared to the activity levels obtained with the single-mutated leaders $\alpha_{\mathrm{A} 20 \mathrm{~T}}$ and $\alpha_{\mathrm{T} 24 \mathrm{~S}}$. Conversely, the use of $\alpha_{\mathrm{A} 20 \mathrm{~T}, \mathrm{~T} 24 \mathrm{~S}}$ leader with PK2 resulted in similar improvement than that obtained with $\alpha_{\mathrm{T} 24 \mathrm{~S}}$. The quadruple mutant $\alpha_{\text {R2S,A9D,A20T,T24S }}$ led to minimal laccase levels (not detectable with PK2 and 0.3-fold with ApL). Surprisingly, $\alpha_{\mathrm{E} 86 \mathrm{G}, \mathrm{A} 87 \mathrm{~T}}$ notably enhanced production of both laccases, around twofold for PK2 and 12-fold for ApL, suggesting a positive epistatic effect between both mutations.

Afterwards, to allow exploration of other possible advantageous combinations between R $\alpha 2 \mathrm{~S}, \mathrm{~A} \alpha 9 \mathrm{D}, \mathrm{A} \alpha 20 \mathrm{~T}$, $\mathrm{T} \alpha 24 \mathrm{~S}, \mathrm{E} \alpha 86 \mathrm{G}$ and $\mathrm{A} \alpha 87 \mathrm{~T}$ mutations, the 6 individual mutants, 3 double and 1 quadruple mutated $\alpha$-factor leaders were subjected to in vivo recombination in $S$. cerevisiae, using PK2 as model laccase (Fig. S3a). After screening 1600 clones of the library, laccase activities were normalized to the activity obtained with the $\alpha_{\text {nat }}$ leader (Fig. S3b). Besides, $\alpha_{\mathrm{E} 86 \mathrm{G}, \mathrm{A} 87 \mathrm{~T}}$ leader was included in the comparison as upper reference because it had produced one of the highest total activity improvements with PK2 (and the highest for ApL, Fig. 3a, b). The five fittest clones carried $\alpha_{A 9 D, A 20 T, T 24 S}$ and $\alpha_{\text {A9D,A20T }}$ leaders. Mutation R $\alpha 2 S$ was discarded for future assays since it seemed to be incompatible with the others (Fig. 3a, b). 


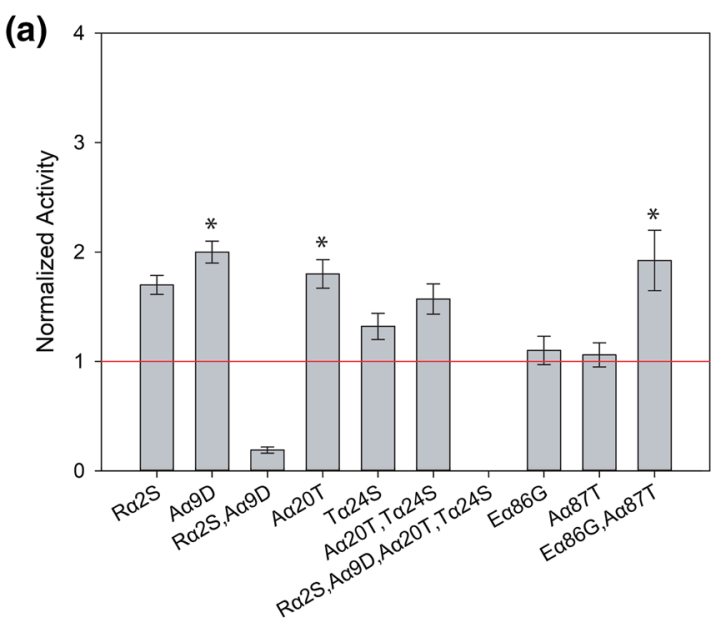

(b)

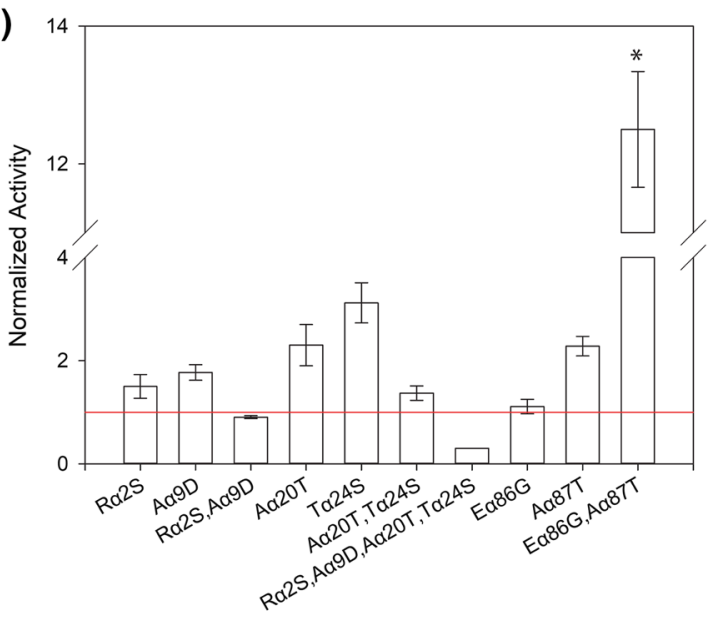

(c)

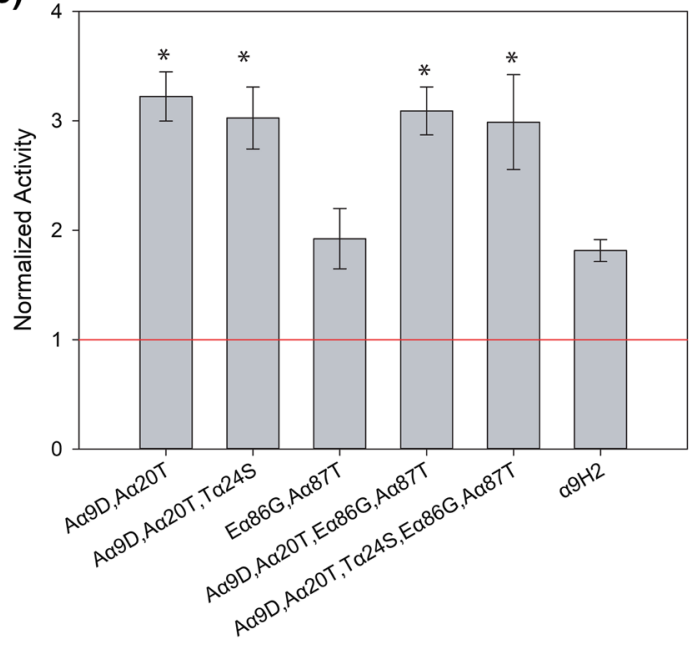

Fig. 3 Laccase activities detected in $S$. cerevisiae microcultures expressing either PK2 (a, c) or ApL (b, d). fused to individual, double and quadruple $\alpha$-preproleader mutants $(\mathbf{a}, \mathbf{b})$, or to the best mutated $\alpha$ leaders $\left(\alpha_{\mathrm{A} 9 \mathrm{D}, \mathrm{A} 20 \mathrm{~T}}\right.$ and $\left.\alpha_{\mathrm{A} 9 \mathrm{D}, \mathrm{A} 20 \mathrm{~T}, \mathrm{~T} 24 \mathrm{~S}}\right)$ and the products of recombination with the second best $\left(\alpha_{\mathrm{E} 86 \mathrm{G}, \mathrm{A} 87 \mathrm{~T}}\right)(\mathbf{c}, \mathbf{d})$. Secreted

Finally, since the combination of the winner set of mutations $\alpha_{\mathrm{A} 9 \mathrm{D}, \mathrm{A} 20 \mathrm{~T}}$ and $\alpha_{\mathrm{A} 9 \mathrm{D}, \mathrm{A} 20 \mathrm{~T}, \mathrm{~T} 24 \mathrm{~S}}$ with one of the best $\left(\alpha_{\text {E86G,A87T }}\right)$ have not been selected from the in vivo DNA recombination assay, we synthesised two final leaders: $\alpha_{\mathrm{A} 9 \mathrm{D}, \mathrm{A} 20 \mathrm{~T}, \mathrm{~T} 24 \mathrm{~S}, \mathrm{E} 86 \mathrm{G}, \mathrm{A} 87 \mathrm{~T}}$ and $\alpha_{\mathrm{A} 9 \mathrm{D}, \mathrm{A} 20 \mathrm{~T}, \mathrm{E} 86 \mathrm{G}, \mathrm{A} 87 \mathrm{~T}}$ to evaluate their joint effect. It was confirmed that $\alpha_{\mathrm{A} 9 \mathrm{D}, \mathrm{A} 20 \mathrm{~T}, \mathrm{~T} 24 \mathrm{~S}}$ and $\alpha_{\mathrm{A} 9 \mathrm{D}, \mathrm{A} 20 \mathrm{~T}}$ leaders significantly raised laccase secretion with respect to $\alpha_{\text {nat }}$ (Fig. 3c, d), being the increment more pronounced with ApL (10-12-fold) than with PK2 (threefold). Conversely, based on Tukey's range test, the production of none of the two laccases tested was improved by the addition of E $\alpha 86 \mathrm{G}$ and $\mathrm{A} \alpha 87 \mathrm{~T}$ mutations to these leaders. We therefore discarded the latter mutations from the final optimised signal peptide. Finally, it was evidenced the neutral effect of T $\alpha 24 \mathrm{~S}$ mutation, so it was discarded as well. In conclusion, (d)

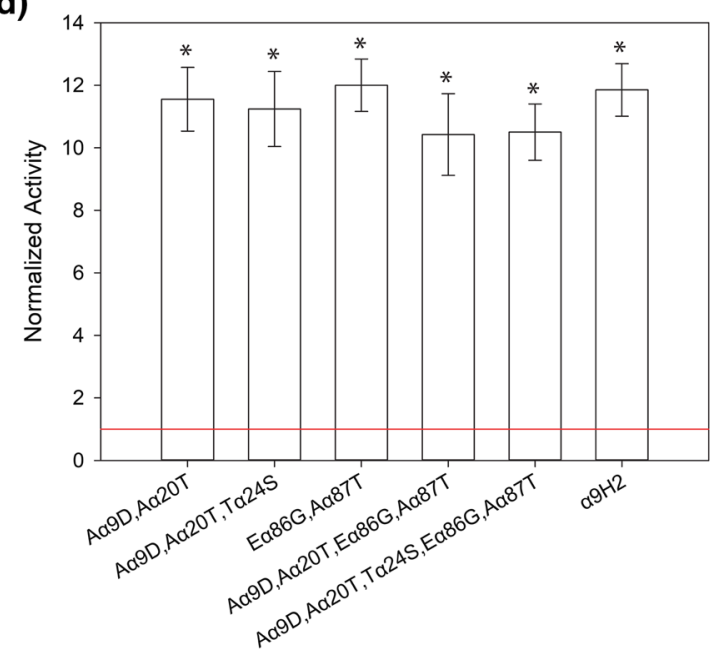

activities were normalized to those of the corresponding parent types: $\alpha_{\text {nat }}-\mathrm{PK} 2$ or $\alpha_{\text {nat }}-\mathrm{ApL}$ (red line). Error bars correspond to the error propagation of ten replicates of each parent type or mutant. Asterisks indicate the highest laccase activities according to Tukey's range test ( $95 \%$ confidence)

we selected $\alpha_{\mathrm{A} 9 \mathrm{D}, \mathrm{A} 20 \mathrm{~T}}$ as the optimised leader from the bottom-up process, because it remarkably surpassed the secretion potential of $\alpha_{\text {nat }}$ leader to values similar (12-fold for $\mathrm{ApL}$ ) or better (threefold for PK2) than those obtained with $\alpha_{9 \mathrm{H} 2}$ leader.

\section{Top-down design of $a_{9 \mathrm{H} 2}$ leader}

In the top-down approach we aimed to obtain an optimised and simplified version of the $\alpha_{9 \mathrm{H} 2}$ leader by removing possible deleterious or neutral mutations that could have been introduced during its in vitro evolution pathway and might mask the effect of beneficial mutations accumulated in the signal peptide. In a first cycle, mutations $\mathrm{Q} \alpha 32 \mathrm{H}, \mathrm{F} \alpha 48 \mathrm{~S}$, $\mathrm{S} \alpha 58 \mathrm{G}$ and G $\alpha 62 \mathrm{R}$ were individually reverted from the $\alpha_{9 \mathrm{H} 2}$ 
(a)

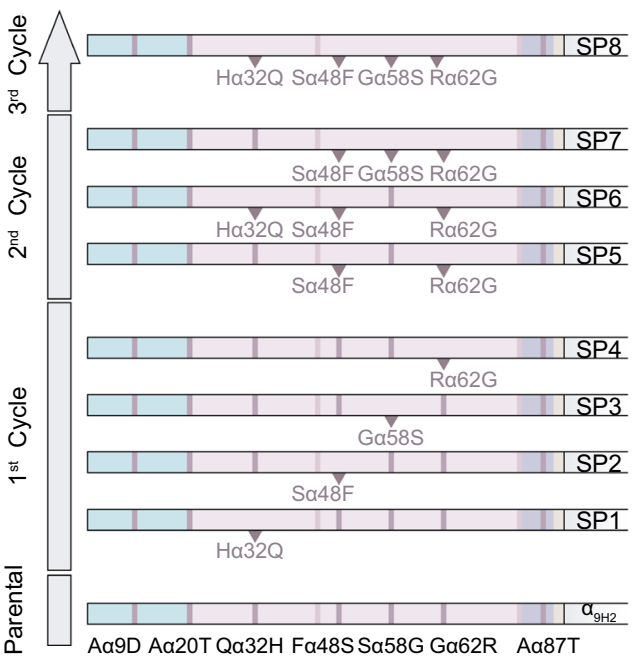

Fig. 4 Top-down strategy over $\alpha_{9 \mathrm{H} 2}$ leader. a Scheme summarizing the three cycles of top-down design of $\alpha_{9 \mathrm{H}_{2}}$ leader directed to improve laccase secretion by removing possible non-beneficial mutations. The removed mutations are highlighted in each $\alpha$ leader sequence (SP1-SP8); colour codes correspond to those shown in Figure 1 . b Laccase activities detected in $S$. cerevisiae microcultures expressing either PK2 (grey bars) or ApL (white bars) fused to the

leader since their neutral effect on laccase secretion were confirmed during the bottom-up approach. The resultant $\alpha$-factor leaders (Signal Peptides) were named as follows:

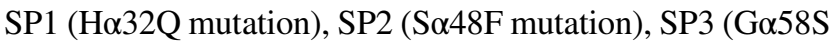
mutation) and SP4 (R $\alpha 62$ G mutation) (Fig. 4a). SP1, SP3 and SP4 had no significant effect on the secretion of PK2 or ApL, as compared to the laccase activities detected with $\alpha_{9 \mathrm{H} 2}$ leader. SP2 did not improved ApL production, but raised 1.3-fold the production of PK2, suggesting a possible deleterious effect of $\mathrm{F} \alpha 48 \mathrm{~S}$ mutation in $\alpha_{9 \mathrm{H} 2}$ leader for secretion of this laccase (Fig. 4b).

In a second evolution cycle, given the aforementioned detrimental effect of $\mathrm{F} \alpha 48 \mathrm{~S}$ mutation in $\alpha_{9 \mathrm{H} 2}$ leader for PK2 laccase (Fig. 4b), and of G $662 \mathrm{R}$ observed in the bottomup approach also for PK2 (Fig. 2), both mutations were simultaneously reverted in SP5. It increased secretion of PK2 similarly to SP2 (with only reversion of F 448 S mutation), whereas no improvement in ApL levels were observed respecting $\alpha_{9 \mathrm{H} 2}$. Two more leaders were designed in parallel to assess the effect of $\mathrm{Q} \alpha 32 \mathrm{H}$ and $\mathrm{S} \alpha 58 \mathrm{G}$ mutations on SP5 environment; each had three reverting mutations: SP6 (H $\alpha 32 \mathrm{Q}, \mathrm{S} \alpha 48 \mathrm{~F}, \mathrm{R} \alpha 62 \mathrm{G})$ and SP7 (S $\alpha 48 \mathrm{~F}, \mathrm{G} \alpha 58 \mathrm{~S}, \mathrm{R} \alpha 62 \mathrm{G})$. Alike SP5, SP6 and SP7 provided similar levels of PK2 than SP2, confirming the detrimental effect of F $\alpha 48$ S mutation on $\alpha_{9 \mathrm{H} 2}$ leader for laccase secretion.

Lastly, the combined absence of the four mutations $\mathrm{Q} \alpha 32 \mathrm{H}, \mathrm{F} \alpha 48 \mathrm{~S}, \mathrm{~S} \alpha 58 \mathrm{G}$ and $\mathrm{G} \alpha 62 \mathrm{R}$ was assayed in SP8 leader. SP8 showed no effect on ApL laccase secretion, different reverted $\alpha_{9 \mathrm{H} 2}$ mutants (SP1-SP8). Laccase activities were normalized to that of the corresponding parent type $\alpha_{\text {nat }}{ }^{-P K} 2$ or $\alpha_{\text {nat }}{ }^{-}$ $\mathrm{ApL}$ (red line). Error bars correspond to the error propagation of ten replicates of each parent type or mutant. One asterisk indicates significant differences respecting the parent type and two asterisks highlight the clone with significant highest activity among all, according to Tukey's range test ( $95 \%$ confidence)

whereas the simultaneous reversion of the four mutations rendered significant higher (1.8-fold) PK2 laccase levels as compared with $\alpha_{9 \mathrm{H} 2}$ leader. Despite the fact that F $\alpha 48 \mathrm{~S}$ seemed to be the only deleterious amino acid change in $\alpha_{9 \mathrm{H} 2}$ leader for PK2 laccase secretion (SP2, Fig. 4b), the four aforementioned mutations have a larger deleterious effect together than separately. Thus, mutations A $\alpha 9 \mathrm{D}, \mathrm{A} \alpha 20 \mathrm{~T}$ and $\mathrm{A} \alpha 87 \mathrm{~T}$ seem to be responsible for the greater secretory potential of $\alpha_{9 \mathrm{H} 2}$ with respect to $\alpha_{\text {nat }}$ leader.

\section{Selection of a final optimised a-factor leader}

The two final leaders selected from the bottom-up $\left(\alpha_{\mathrm{A} 9 \mathrm{D}, \mathrm{A} 20 \mathrm{~T}}\right)$ and top-down $\left(\alpha_{\mathrm{A} 9 \mathrm{D}, \mathrm{A} 20 \mathrm{~T}, \mathrm{~A} 87 \mathrm{~T}}\right)$ pathways were compared for secretion of ApL and PK2 laccase by S. cerevisiae cultured in flasks. The $\alpha_{\text {nat }}$ and $\alpha_{9 \mathrm{H} 2}$ leaders were included in the assay as lower and upper references. In this case, the minimum laccase expression medium (SEM) utilised in the micro-fermentations was replaced by a richer medium (EB) because the reduced growth of the yeast in SEM could limit laccase production in flasks [45]. We aimed as well to check the reproducibility of the results obtained in other culture medium and conditions. Optical densities (Fig. S4) and laccase activities (Fig. 5) of the cultures were monitored for 4 days. All $S$. cerevisiae clones grew similarly, but they produced dissimilar laccase activities. After 4 days of incubation, $\alpha_{\text {A9D,A20T,A87T }}$ leader fused to PK2 laccase provided up to $4800 \mathrm{U} / \mathrm{L}$ with $\mathrm{ABTS}$, while $\alpha_{\mathrm{A} 9 \mathrm{D}, \mathrm{A} 20 \mathrm{~T}}$ 

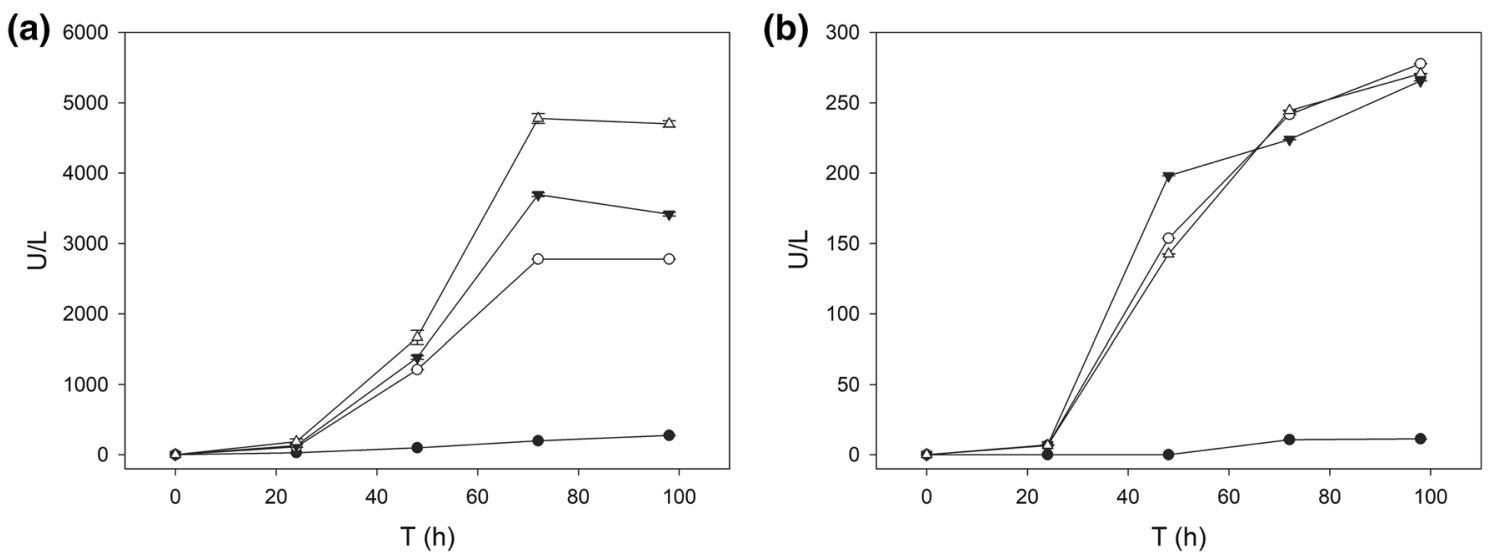

$\bullet \alpha_{\text {nat }} \multimap-\alpha_{9 H 2} \longrightarrow \alpha_{A 9 D, A 20 T} \backsim \alpha_{A 9 D, A 20 T, A 87 T}$

Fig. 5 Flask production of PK2 (a) and ApL (b) laccases by S. cerevisiae with the best $\alpha$-factor leaders obtained in the bottom-up $\left(\alpha_{\mathrm{A} 9 \mathrm{D}, \mathrm{A} 20 \mathrm{~T}}\right)$ and top-down $\left(\alpha_{\mathrm{A} 9 \mathrm{D}, \mathrm{A} 20 \mathrm{~T}, \mathrm{~A} 87 \mathrm{~T}}\right)$ designing strategies com-

yielded around $3700 \mathrm{U} / \mathrm{L}$, which respectively represent 18 -fold and 14-fold higher activities than that detected with $\alpha_{\text {nat }}$ leader, and 1.8-fold and 1.4-fold improvements respecting laccase levels detected with $\alpha_{9 \mathrm{H} 2}$ leader (Fig. 5a). On the other hand, $\alpha_{\mathrm{A} 9 \mathrm{D}, \mathrm{A} 20 \mathrm{~T}, \mathrm{~A} 87 \mathrm{~T}}, \alpha_{\mathrm{A} 9 \mathrm{D}, \mathrm{A} 20 \mathrm{~T}}$ and $\alpha_{9 \mathrm{H} 2}$ leaders fused to ApL gave rise to similar laccase levels (around $260 \mathrm{ABTS}$ $\mathrm{U} / \mathrm{L}$ ), which represent a 26 -fold improvement respecting the laccase activity detected with $\alpha_{\text {nat }}$ (Fig. 5b). The superior secretory potential of the three engineered leader sequences with respect to $\alpha_{\text {nat }}$ was therefore confirmed. Furthermore, the similar (ApL) or markedly improved (PK2) laccase levels obtained with the optimised leaders with respect to the $\alpha_{9 \mathrm{H} 2}$ leader, pointed out the essential role that $\mathrm{A} \alpha 9 \mathrm{D}$ and A $\alpha 20 \mathrm{~T}$ mutations play in the superior secretory capability of $\alpha_{9 \mathrm{H} 2}$ leader. By contrast, the dissimilar results obtained with $\alpha_{\mathrm{A} 9 \mathrm{D}, \mathrm{A} 20 \mathrm{~T}}$ or $\alpha_{\mathrm{A} 9 \mathrm{D}, \mathrm{A} 20 \mathrm{~T}, \mathrm{~A} 87 \mathrm{~T}}$ in the production of the two laccases suggested that the variable effect exerted by A $\alpha 87 \mathrm{~T}$ mutation may be influenced by the sequence of the fused protein.

Taking all this into account, $\alpha_{\mathrm{A} 9 \mathrm{D}, \mathrm{A} 20 \mathrm{~T}}$ was selected over $\alpha_{\text {A9D,A20T,A87T }}$ leader. Since $\alpha_{\text {A9D,A20T }}$ leader carried also mutations L $\alpha 42 \mathrm{~S}$ and D $\alpha 83 \mathrm{E}$ (Invitrogen), we double checked their contribution in $\alpha_{\mathrm{A} 9 \mathrm{D}, \mathrm{A} 20 \mathrm{~T}}$ leader context by individually discarding them from the selected leader fused to PK2 and ApL. As previously shown, the absence of L $\alpha 42 S$ had a strong negative effect on laccase production (0.5-fold reduction), whereas we confirmed the neutral effect of D $\alpha 83 \mathrm{E}$ (Fig. S5). Mutations A $\alpha 9 \mathrm{D}, \mathrm{A} \alpha 20 \mathrm{~T}, \mathrm{~L} \alpha 42 \mathrm{~S}$, D $\alpha 83 \mathrm{E}$ were included in the optimised all-purpose leader for further assays, named $\alpha_{\mathrm{OPT}}$ from now on. pared with $\alpha_{\text {nat }}$ and $\alpha_{9 \mathrm{H} 2}$ leaders Laccase activity (U/L) was measured with ABTS $\mathrm{pH} 3$. Error bars indicate standard derivation of three flask replicates

\section{Expression of other enzymes}

The secretory potential of $\alpha_{\mathrm{OPT}}$ leader was evaluated for the production by $S$. cerevisiae of other fungal oxidoreductases like two more laccases from Pleurotus eryngii (PeL) [46] and Pycnoporus cinnabarinus (PcL) [32], an aryl-alcohol oxidase from $P$. eryngii (AAO) [47] and a versatile peroxidase (VP) from P. eyringii [48]. Besides, we assayed it with fungal hydrolases such as two $\beta$-glycosidases (BGL2 and BGL3) from Talaromyces amestolkiae [49, 50] and a sterol esterase (OPE) from Ophiostoma piceae [51]. To this aim, the native signal peptides were removed and replaced by $\alpha_{\mathrm{OPT}}, \alpha_{\text {nat }}$ and $\alpha_{9 \mathrm{H} 2}$ leaders for enzyme expression in $S$. cerevisiae (the two latter used as lower and upper references). Yeast cells (ten replicates of each clone) were grown in 96-well plates in SEM, and the secreted enzyme activities were measured and normalized to the activities obtained with $\alpha_{\text {nat }}$ leader (Fig. 6).

In general, $\alpha_{\mathrm{OPT}}$ leader provided enzyme secretion levels significantly higher than those obtained with $\alpha_{\text {nat }}$ leader. In some cases, the increments in enzyme production obtained with $\alpha_{\mathrm{OPT}}$ leader were remarkable: $10-20$-fold higher levels for PeL, PcL, ApL and OPE than those obtained with $\alpha_{\text {nat }}$ leader (Fig. 6). As regards $\alpha_{9 \mathrm{H} 2}$ leader, it significantly enhanced the production of all tested laccases respecting the use of $\alpha_{\text {nat }}$ leader, but to a lower or at most similar extend than $\alpha_{\mathrm{OPT}}$ leader. Moreover, $\alpha_{9 \mathrm{H} 2}$ performance with the rest of enzymes was not as good, being in general similar or worse than $\alpha_{\text {nat }}$ leader (e.g. 0.35-fold for VP and 0.07-fold for AAO). Taking all this into account, $\alpha_{\mathrm{OPT}}$ leader emerges as a general signal peptide suited for efficient expression of fungal enzymes in S. cerevisiae. 


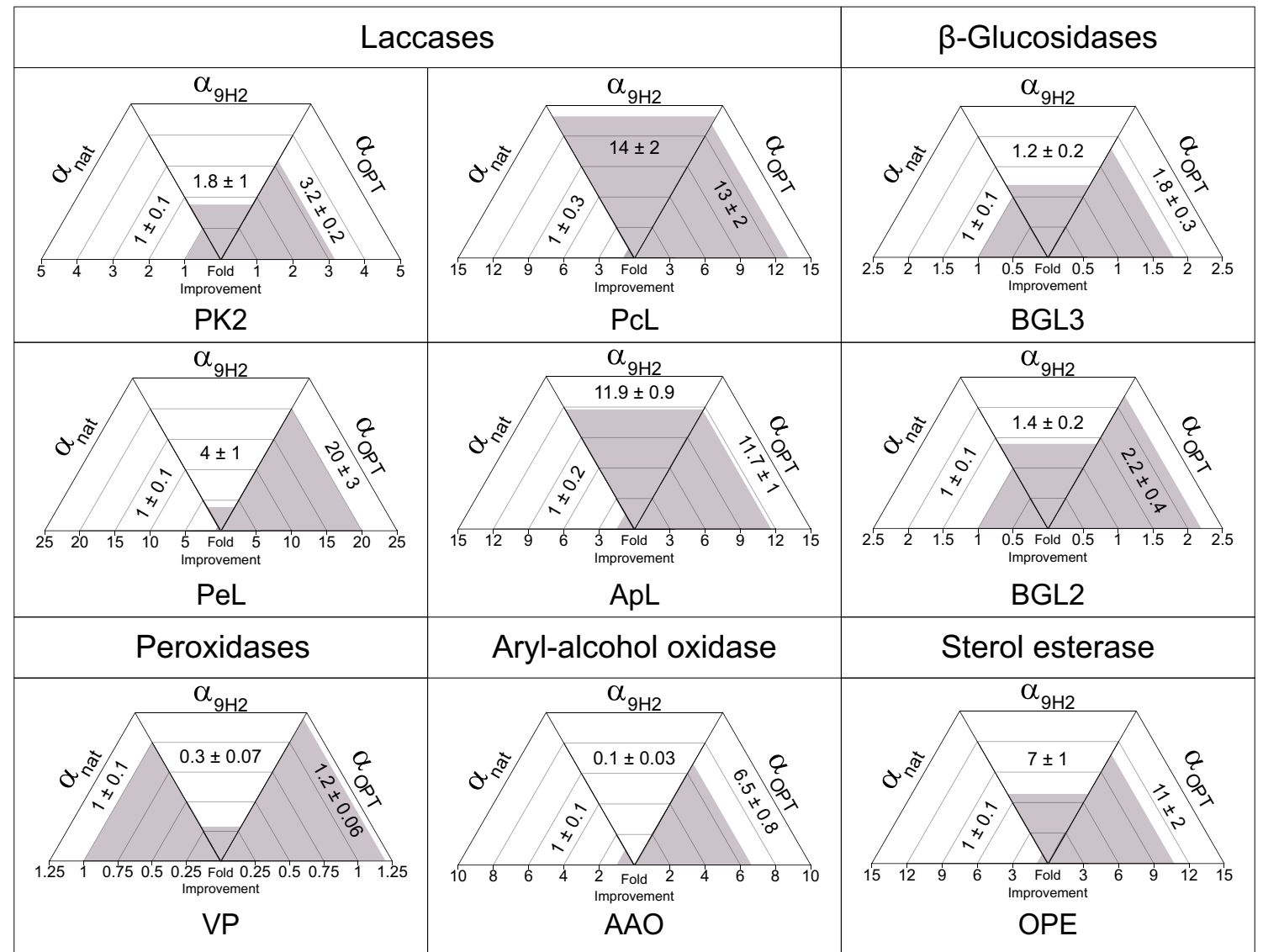

Fig. 6 Enzyme production by $S$. cerevisiae cultured in 96-well plates using $\alpha_{\text {nat }}, \alpha_{9 \mathrm{H} 2}$ or $\alpha_{\mathrm{OPT}}$ leaders. Secreted enzymatic activities of laccases (PK2, ApL, PeL, and PcL), aryl-alcohol oxidase (AAO), peroxidase (VP), $\beta$-glucosidases (BGL2 and BGL3) and sterol esterase

\section{Combinatorial saturation mutagenesis on the spacer region}

Mutations E $\alpha 86 \mathrm{G}$ and $\mathrm{A} \alpha 87 \mathrm{~T}$ were ruled out from the aforementioned "universal" $\alpha_{\mathrm{OPT}}$ leader due to their dissimilar effect on secretion of ApL or PK2 laccases which might be related to the different fused protein sequences. We hypothesised that positions 86th and 87th of the spacer region would play a crucial role in the secretory potential of the signal peptide, and, therefore, they may well be hotspots for engineering the $\alpha$ leader towards the production of a particular recombinant enzyme. To test this hypothesis, positions 86th and 87th of $\alpha_{\text {OPT }}$ leader fused either to PK2 or ApL were subjected to combinatorial saturation mutagenesis (CSM), covering all possible amino acid combinations, and the activities of the mutant libraries expressed in $S$. cerevisiae were screened with ABTS. Population of clones with parental-like activity (inside parent's confidence interval) were minor in both CSM 86/87 libraries, whereas most clones (53\% for PK2 and 69\% for ApL) exhibited lower activity than parental $\alpha_{\mathrm{OPT}}$ leader, and clones with higher
(OPE) are indicated as fold improvements with respect to the activities obtained with $\alpha_{\text {nat }}$ leader. Error correspond to the error propagation of ten replicates of each construction (with $\alpha_{\text {nat, }} \alpha_{9 \mathrm{H} 2}$ or $\alpha_{\mathrm{OPT}}$ )

laccase activities represent a 32\% in PK2 library and 5\% in ApL library (Fig. 7a).

On the other hand, we randomised positions 58/59 and $68 / 69$ of two $N$-glycosylation sites (Asn in positions 57 th and 67th) of the pro-region of the $\alpha$ leader $[19,52]$, in such a way that the consensus pattern Asn-X-Ser/Thr was conserved. While Asn was maintained, positions 58 and 68 were mutated by whatever amino acid except for Pro and positions 59 and 69 were restricted to Ser or Thr. We used the resulting CSM $N$-Gly58/59 and $N$-Gly68/69 libraries (built on $\alpha_{\mathrm{OPT}}-\mathrm{PK} 2$ and $\alpha_{\mathrm{OPT}}-\mathrm{ApL}$ ) as reference of presumably neutral libraries, and compared the results from their screening with those obtained from the CSM86/87 libraries under the criteria "the larger population of clones with parental-like activity, the less impact the mutated sites have on enzyme secretion". By contrast to CSM 86/87 libraries, most of the clones (50-60\%) exhibited parental-like activities (Fig. 7a), confirming that the 2 nd position of $\mathrm{N}$-glycosylation sites was not so relevant for $\alpha$ leader engineering as 86th and 87 th positions were. In addition, although clones with improved activities were also found in CSM N-Gly58/59 and 68/69 
(a)

CSM over PK2

\begin{tabular}{ccccc}
\cline { 4 - 4 } Higher & $86 / 87$ & \multicolumn{2}{c}{ N-Gly58/59 } & N-Gly68/69 \\
\cline { 2 - 4 } \cline { 4 - 4 } & $32 \%$ & $11 \%$ & $24 \%$ \\
\hline Equal & $15 \%$ & $54 \%$ & $54 \%$ \\
\hline Lower & $53 \%$ & $35 \%$ & $22 \%$ \\
\hline
\end{tabular}

(b)

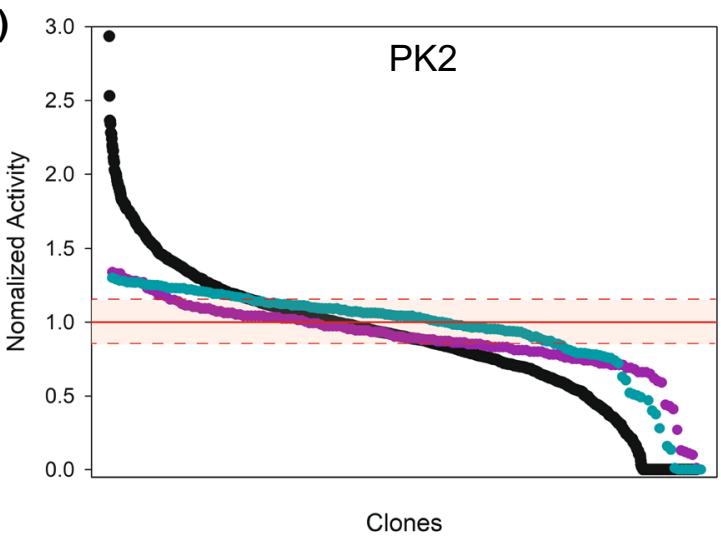

\begin{tabular}{cccc} 
& \multicolumn{3}{c}{ CSM over ApL } \\
\cline { 2 - 4 } & $86 / 87$ & N-Gly58/59 & N-Gly68/69 \\
\cline { 2 - 4 } Higher & $5 \%$ & $20 \%$ & $25 \%$ \\
\hline Equal & $26 \%$ & $61 \%$ & $50 \%$ \\
\hline Lower & $69 \%$ & $19 \%$ & $22 \%$ \\
\hline
\end{tabular}

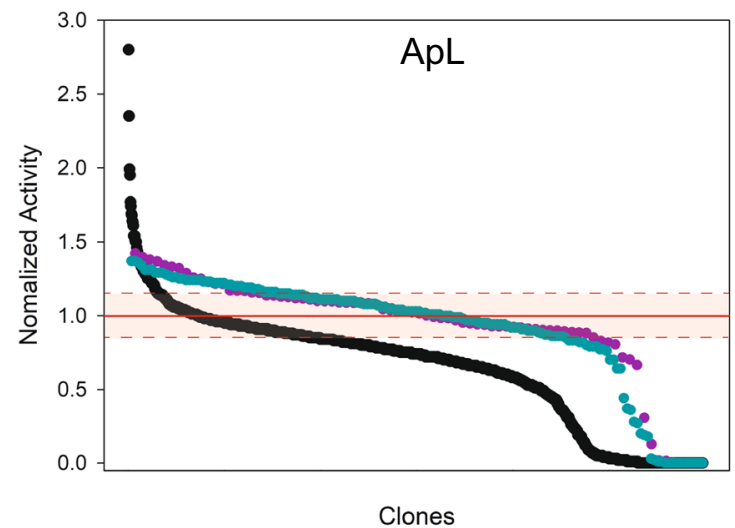

(c)

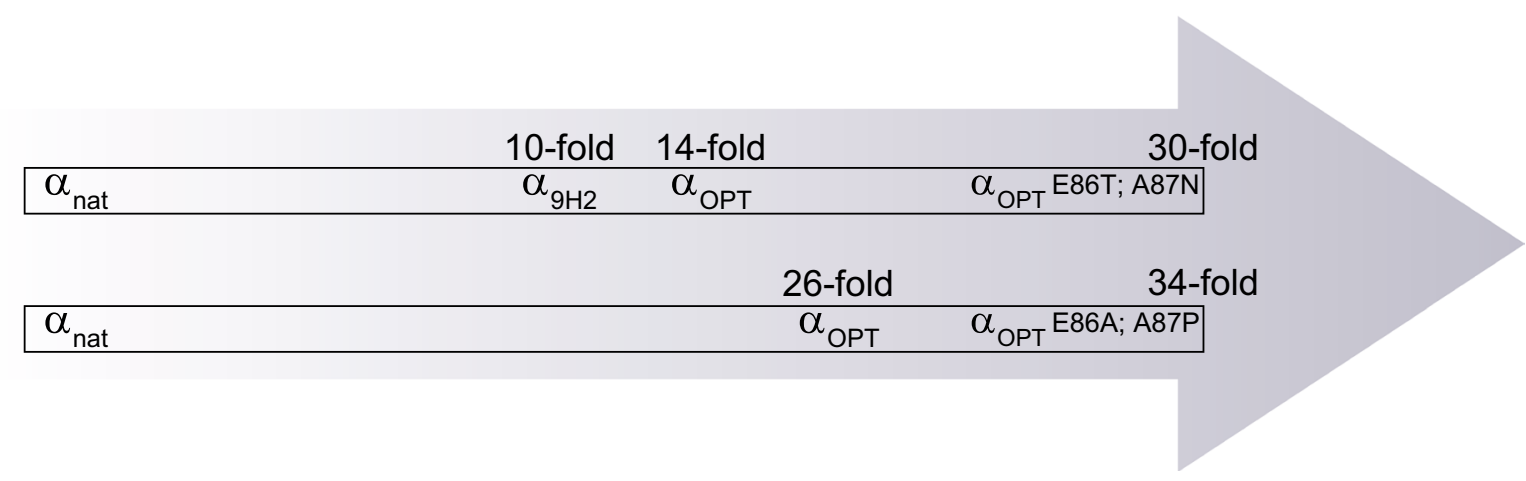

Fig. 7 a Percentages of clones with higher, lower or parent-like activities of mutant libraries obtained upon mutation of positions 86th and 87 th of the spacer region (black) and on the 2nd and 3rd positions of NXT/S sequence of the $N$-glycosylation sites 57 (purple) and 67 (cyan) of $\alpha_{\text {OPT }}$ leader for secretion of laccases PK2 and ApL (interval of Confidence of 95\%). b Activity landscapes of the aforementioned CSM86/87, CSM-NGly58/59 and CSM-NGly68/69 mutant

libraries, the improvements detected were significantly lower. Moreover, the plain shape of their activity landscapes remarks the "neutral" nature of these libraries by contrast with the hill trend of CSM86/87 landscapes (Fig. 7b).

The best amino acid substitutions selected from each CSM 86/87 library were different for PK2 laccase (E $\alpha 86 \mathrm{~T} /$ $\mathrm{A} \alpha 87 \mathrm{~N} ; \mathrm{E} \alpha 86 \mathrm{D} / \mathrm{A} \alpha 87 \mathrm{~N}$ and $\mathrm{E} \alpha 86 \mathrm{D} / \mathrm{A} \alpha 87 \mathrm{G})$ and $\mathrm{ApL}$ (E $\alpha 86 \mathrm{~A} / \mathrm{A} \alpha 87 \mathrm{P} ; \mathrm{E} \alpha 86 \mathrm{~T} / \mathrm{A} \alpha 87 \mathrm{~K}$ and $\mathrm{E} \alpha 86 \mathrm{~S} / \mathrm{A} \alpha 87 \mathrm{R})$. The libraries of $\alpha_{\mathrm{OPT}}$ leader fused to laccases PK2 or ApL. The activities of the clones are shown as relative to the laccase activities obtained with $\alpha_{\mathrm{OPT}}$ leader (depicted as 1 ); the interval of confidence of the CSM86/87 assay is indicated with dashed lines. c Secretion improvements for PK2 (top) and ApL (bottom) obtained throughout $\alpha$-factor preproleader engineering, from $\alpha_{\text {nat }}$ to $\alpha_{\mathrm{OPT}}$ mutated in $86 / 87$

clones providing the highest secreted activity improvements $\left(\alpha_{\text {OPT E } \alpha 86 \mathrm{~T} / \mathrm{A} \alpha 87 \mathrm{~N}}\right.$ for PK2 and $\alpha_{\mathrm{OPT} \text { E } \alpha 86 \mathrm{~A} / \mathrm{A} \alpha 87 \mathrm{P}}$ for ApL) were cultivated in flask to test laccase production. Production of PK2 laccase was raised roughly twofold and 30 -fold as compared with the activity levels provided by $\alpha_{\mathrm{OPT}}$ leader and $\alpha_{\text {nat }}$ leader, respectively; while for ApL production, the improvements were around 1.3-fold and 34-fold, respectively (Fig. 7c). 
Finally, we purified PK2 laccase produced with $\alpha_{\mathrm{OPT}}$ and $\alpha_{\text {OPT E } \alpha 86 \mathrm{~T} / \mathrm{A} \alpha 87 \mathrm{~N}}$ as leaders in $S$. cerevisiae flask cultures (Fig. S6). In both cases, after deglycosylation with Endo $\mathrm{H}$, the enzyme showed a molecular weight around $53 \mathrm{KDa}$, coincident with its theoretical MW (Fig. S7). The enzymes purified from both cultures showed also identical specific activities with ABTS regardless of the signal peptide used: $405 \pm 23 \mathrm{U} / \mathrm{mg}$ and $423 \pm 34 \mathrm{U} / \mathrm{mg}$ for the enzyme secreted with $\alpha_{\mathrm{OPT}}$ and $\alpha_{\mathrm{OPT} \text { E } \alpha 86 \mathrm{~T} / \mathrm{A \alpha} \alpha 7 \mathrm{~N}}$, respectively. With this data and the laccase activity units detected in the culture broths ( $2800 \mathrm{U} / \mathrm{L}$ with $\alpha_{\mathrm{OPT}}$ and $4800 \mathrm{U} / \mathrm{L}$ with $\alpha_{\mathrm{OPT} \text { E } \alpha 86 \mathrm{~T} / \mathrm{A} \alpha 87 \mathrm{~N}}$ ), we determined that the total $\mathrm{mg}$ of PK2 laccase secreted with $\alpha_{\mathrm{OPT} \text { E } \alpha 86 \mathrm{~T} / \mathrm{A} \alpha 87 \mathrm{~N}}$ was roughly twice as high the amount of enzyme secreted with $\alpha_{\mathrm{OPT}}$.

\section{Discussion}

We present here the designing of an optimised version of the $\alpha$-factor preproleader from S. cerevisiae to improve the production of fungal enzymes by the yeast. The $\alpha_{9 \mathrm{H} 2}$ leader developed in our lab [42] was selected as reference signal peptide because this mutated leader significantly improves the secretion by S. cerevisiae of several laccases compared with other evolved $\alpha$ leaders obtained in our lab [46], or with the $\alpha_{\text {nat }}$ leader (Invitrogen) as shown here for PK2 and ApL. Thus, we studied the effect of the mutations accumulated in $\alpha_{9 \mathrm{H} 2}$ leader sequence through its evolution pathway as well as other mutations of the $\alpha$-factor preproleader selected (and eventually lost) during successive laccase directed evolution campaigns $[32,33,42,44]$

Two engineering pathways of the signal peptide were carried out: a bottom-up designing strategy on $\alpha_{\text {nat }}$ leader and a top-down one on $\alpha_{9 \mathrm{H} 2}$ leader using PK2 and ApL laccases as model enzymes. In total, 13 candidate mutations were assayed (alone or combined) until both approaches met to obtain the optimised leader $\alpha_{\text {OPT }}$. The superior secretory potential exhibited by $\alpha_{\mathrm{OPT}}$ leader, as compared with $\alpha_{\text {nat }}$ or $\alpha_{9 \mathrm{H} 2}$ leaders in different media and culture conditions, arises from the accumulation of four mutations, two beneficial mutations A $\alpha 9 \mathrm{D}, \mathrm{A} \alpha 20 \mathrm{~T}$ from $\alpha_{9 \mathrm{H} 2}$ leader, and L $\alpha 42 S$, D $\alpha 83 \mathrm{E}$ from $\alpha_{\text {nat }}$ leader (Invitrogen). Actually, the L $\alpha 42 S$ mutation is clearly beneficial as demonstrated by the significantly diminished laccase secretion levels when it was reverted in $\alpha_{\text {nat }}$ and $\alpha_{\mathrm{OPT}}$ leaders; whereas reversion of D $\alpha 83$ E mutation had a neutral effect. Despite this, we opted to maintain it as well, given it was also present in the original $\alpha_{\text {nat }}$ leader and it adds an XhoI cleavage site to facilitate further genetic engineering.

Mutation L $\alpha 42 \mathrm{~S}$ is absent in the original $\alpha$-factor preproleader sequence [15] as well as in the MF $\alpha 1$ of S288C strain, the first $S$. cerevisiae genome released in 1996 [53, 54]. Moreover, mutations L $\alpha 42 \mathrm{~S}, \mathrm{D} \alpha 83 \mathrm{E}$ are not found in none of the MF $\alpha 1$ sequences from $S$. cerevisiae strains available in Saccharomyces Genome Database (SGD; https ://www.yeastgenome.org) (Fig. S8). Interestingly, L $\alpha 42 \mathrm{~S}$ mutation come out when MF $\alpha 1$ S. cerevisiae gene was first simultaneously sequenced in two works $[15,16]$. Both articles published in agreement the same tandem gen structure sequence except for 42nd residue, which was a Ser in Kurjan and Herskowitz [16] instead of the Leu found in the sequence published by Singh and co-workers [15] and in the rest of $M F \alpha 1$ sequences published afterwards. From a population of 50,000 transformed cells with YEp13 plasmid containing the expected MF $\alpha 1$ gene, Kurjan and Herskowitz selected a possible $\alpha$-mating factor overproducer colony based on morphology criteria. Thus, and according to our own results, it is most probable that $\mathrm{L} \alpha 42 \mathrm{~S}$ mutation comes from a random mutational event and it would have conferred a dominant phenotype to this single colony, favouring its selection [16].

As evidenced by our results, most mutations entailing a favourable effect on the heterologous production of both laccases were located at or near the pre-region (except for mutation L $\alpha 42 S$ located in the pro-region). Single mutations $\mathrm{A} \alpha 9 \mathrm{D}$ and $\mathrm{A} \alpha 20 \mathrm{~T}$, from $\alpha_{9 \mathrm{H} 2}$ leader, and $\mathrm{R} \alpha 2 \mathrm{~S}$ and T $\alpha 24 S$ recovered from PcL directed evolution pathway [32], were proved to be beneficial during the bottom-up pathway. Interestingly, the beneficial effect of R $\alpha 2 \mathrm{~S}$ confronts the commonly assumed requirement for the presence of positive charged residues at the amino terminal of signal peptides [10]. In this line, mutation $\mathrm{R} \alpha 2 \mathrm{~F}$ had been reported to have a neutral effect on somatostatin production, whereas the substitution of the third residue by a positive charged amino acid seriously attenuated the translocation across the ER membrane [55]. These results highlight the influence of first residues of the $\alpha$-factor preproleader, although positively charged amino acids might not be mandatory. The latter seems to be more crucial in bacterial signal peptides, since in Eukaryotes the terminal Met is unformulated and remains positively charged, which seems to be enough to ensure the proper operation of eukaryotic signal peptides [56]. Nevertheless, the counteracting effect of $R \alpha 2 S$ and A $\alpha 9$ D mutations put together (Fig. 3a, b), supported by the absence of the R $\alpha 2 S$ and A $\alpha 9 \mathrm{D}$ combination in the fittest $\alpha$-factor leader variants selected from the recombination library (Fig. S3), discarded R $\alpha 2$ S mutation for the final $\alpha_{\text {OPT }}$. This detrimental effect of R $\alpha 2 \mathrm{~S}, \mathrm{~A} \alpha 9 \mathrm{D}$ combination had been suggested during PcL directed evolution, where both mutations were selected separately but never simultaneously during the screening of DNA recombination libraries [32].

Mutation A $\alpha 9 \mathrm{D}$ provided remarkable improvements on enzyme secretion, regardless of the laccase attached to the signal peptide and in cooperation with A $\alpha 20 \mathrm{~T}$. Beneficial mutations in the hydrophobic core of the pre-region of the $\alpha$-factor leader had been selected during the directed 
evolution of fungal laccases for functional expression in S. cerevisiae. Mutation $\mathrm{V} \alpha 10 \mathrm{D}$ was selected during the directed evolution of PM1L where it notably raised the laccase activity detected in the supernatants [33]. In parallel, A $\alpha 9 \mathrm{D}$ stood out as the mutation of the $\alpha$-factor preproleader responsible for the highest laccase improvement during PcL directed evolution [32]. Moreover, other mutation reducing the hydrophobicity of these positions ( $\mathrm{V} \alpha 10 \mathrm{~A})$ had been selected during the design of $\alpha$-factor preproleader for antibody expression in S. cerevisiae [20]. Despite the hydrophobic core has been described to facilitate a proper translocation of the peptide into the endoplasmic reticulum $[12,57,58]$, a shift towards hydrophilicity seems to be the only common element in the aforementioned amino acid substitutions (A $\alpha 9 \mathrm{D}, \mathrm{V} \alpha 10 \mathrm{D}, \mathrm{V} \alpha 10 \mathrm{~A})$. This trend was also observed in the $\alpha$-factor preproleader from YJM339 S. cerevisiae strain (available at SGD) which held mutation $\mathrm{A} \alpha 9 \mathrm{~T}$ [59] (Fig. S8).

Mutation A $\alpha 20 \mathrm{~T}$ produced good results similar to those obtained with A $\alpha 9 \mathrm{D}$. The role of the former mutation seems to underlie in its location immediately before the cleavage site, between pre and pro-regions. In concordance with the consensus classical signal peptide structure, the pre-region conserves the AXA motif at the -1 and -3 positions relative to the cleavage site (Ala17-Leu18-Ala19) [24, 60]. A $\alpha 20 \mathrm{~T}$ is likely to increase the efficiency of protease cleavage which is expected to be a limiting step in the secretion of some proteins [61]. Even though T $\alpha 24 \mathrm{~S}$ mutation alone has a favourable effect on laccase secretion similar to that of $A \alpha 20 \mathrm{~T}$, no positive synergism between both mutations could be found (Fig. 3a, b). This added to its negligible effect on $\alpha_{\mathrm{OPT}}$ leader context (Fig. 3c, d) led us to discard T $\alpha 24$ S. Mutations $\mathrm{T} \alpha 24 \mathrm{~S}$ and $\mathrm{S} \alpha 58 \mathrm{G}$ are in first and second $\mathrm{N}$-glycosylation sites of the signal peptide, specifically in the second position of the $\mathrm{N}$-Gly consensus sequence (N-X-T/S). Replacement of this variable second residue may alter the affinity for sugar anchoring [62, 63]. However, in view of the results obtained from the bottom-up and top-down designing strategies with S $\alpha 58$ G mutation (Figs. 2 and 4), and the absence of relevant improvements on secretion of PK2 and ApL laccases in the mutants selected from CSM ( $N$-Gly58/59 and $N$-Gly68/69 libraries), contribution of the second position of $\mathrm{N}$-glycosylation sites to the secretory capability of the $\alpha$-factor preproleader seems to be insignificant in comparison with other amino acid substitutions shown here.

Most of the studied mutations of the pro-region $\mathrm{Q} \alpha 32 \mathrm{H}$, L $\alpha 44 S, F \alpha 48 S, S \alpha 58 G, G \alpha 62 R$, D $\alpha 83 E$, exhibited either neutral or deleterious effects on enzyme production, depending on the attached laccase. In this line, the larger detrimental effect of Q $\alpha 32 \mathrm{H}, \mathrm{F} \alpha 48 \mathrm{~S}, \mathrm{~S} \alpha 58 \mathrm{G}, \mathrm{G} \alpha 62 \mathrm{R}$ mutations put together, for PK2 secretion, pointed out the relevance of the strategy we followed to detect negative epistasis among mutations. Only L $\alpha 42 \mathrm{~S}$ mutation positively contributed to
ApL and PK2 secretion, while D $\alpha 83 \mathrm{E}$ mutation (both coming from the original $\alpha_{\text {nat }}$ leader of Invitrogen) resulted neutral, in agreement with the effects observed for both mutations during GFP expression in Pichia pastoris [35]. The contribution of the pro-region to the overall function of the $\alpha$-factor preproleader had been proved through deletion of the entire pro-region, which severely reduces the processing of the foreign enzyme in S. cerevisiae [64]. It has been also concluded that certain consecutive residues seem to ensure the proper functionality of the pro-region $[12,20]$. The main disagreement lies on its precise function, either facilitating translocation across the ER lumen [12,13], or acting as an ER exporting signal in a COPII vesicle-dependent way by means of the Erv29 protein recognition in S. cerevisiae [22, $25,26]$. Even when a definitive statement about the proregion function cannot be given, all of the above points out the importance of some particular residues of this region. More specifically, mutation in the 42th position recurrently appears in the literature, supporting our results [20, 25, 35]. The potential of 42th and adjacent positions were reported in 2016 in the WO2015128507 patent [65], which contained a method for recombinant expression of a glucagon-like peptide-1 using $\alpha$-factor preproleader variants bearing substitutions at 38-42 residues, including mutation L $\alpha 42 \mathrm{~S}$.

Shortcomings during KEX2 processing, derived in either over-saturation or inefficient cut, constitute a bottleneck in foreign protein secretion $[66,67]$. STE13 protease seems not to be as crucial as KEX2, since several proteins retaining an extra $\mathrm{N}$-terminus amino acid tail related to inefficiency of protease processing resulted in overexpression of the recombinant protein [34, 44, 68, 69]. Optimizing KEX2 cleavage site or integrating additional constitutively expressing KEX2 emerged as possible strategies to remove the aforementioned bottle neck [67]. However, the optimization of the cleavage site seems difficult given its fixed dibasic Lys84-Arg85 sequence that does not accept any substitution apart from R $\alpha 85 \mathrm{~K}[67,70,71]$. On the other hand, there are evidences about the importance of residues downstream the KEX2 cleavage site and before the mature protein $[66,72,73]$. This spacer region is variable in length and shows negatively charged amino acids in the four tandem genes [Lys-Arg(Glu/Asp-Ala) ${ }_{2-3}$ ] of MF $\alpha 1$ gene, which shines light on its possible optimization.

Consistent with the above data, mutations E $\alpha 86 \mathrm{G}, \mathrm{A} \alpha 87 \mathrm{~T}$ of the spacer region increased protein secretion yields, although with dissimilar results for ApL and PK2 laccases. However, their negligible positive effect in $\alpha_{\mathrm{OPT}}$ context led us to discard them from the final optimised signal peptide. We hypothesised that the enzyme secretion could be significantly raised by randomising 86th and 87th positions of the $\alpha_{\mathrm{OPT}}$ leader, being the amino acid substitutions most likely selected in the context of the fused protein. The contribution of these positions to tune the secretory potential of $\alpha_{\mathrm{OPT}}$ 
was assessed through CSM of both positions, exploring the secretion of ApL and PK2 laccases. The CSM 86/87 libraries were compared with CSM $N$-Gly58/59 and $N$-Gly68/69 libraries designed in such a way that the $N$-glycosylation pattern required for pro-peptide processing $[19,52]$ was preserved. The activity landscapes of the CSM $N$-Gly libraries showed a clear predominance of clones with parental-like activities, confirming they were "neutral" libraries. By contrast, the low number of clones with parental-like activities found in CSM 86/87 libraries underlined the higher evolvability of positions $86 / 87$. First, the significant laccase activity improvements found in a percentage of clones of both CSM 86/87 libraries evidenced that positions 86/87 constitute hotspots for engineering the $\alpha$ leader to improve enzyme secretion. Second, selection of different fittest 86/87 amino acid pairs for improving the secretion of PK2 or ApL, supported our hypothesis that these positions have to be optimised specifically for a given protein. In fact, the modest number of clones with improved activities found in CSM 86/87 library for ApL (5\%) can be attributed to the presence of an already suited amino acid pair in $\alpha_{\mathrm{OPT}}$ leader for the secretion of this laccase in particular. This is in agreement with results from saturation mutagenesis on 86th position of the $\alpha$-factor preproleader that depended on the protein attached [67].

On the other hand, the purification and characterisation of PK2 laccase produced with $\alpha_{\mathrm{OPT}}$ or $\alpha_{\mathrm{OPT} \text { E } \alpha 86 \mathrm{~T} / \mathrm{A} \alpha 87 \mathrm{~N}}$ as signal peptides, allowed us to confirm that the enzyme had been equally processed and it has the same catalytic activity, regardless of whether positions $86 / 87$ of the signal peptide had been optimised or not. After deglycosylation with Endo $\mathrm{H}$, the enzyme showed a MW coincident with its theoretical MW, indicating the cleavage of the pro-region by KEX2 in both signal peptides. Also, the equal catalytic activity of the enzyme produced with $\alpha_{\text {OPT }}$ or $\alpha_{\text {OPT E } \alpha 86 T / A \alpha 87 N}$ confirmed that the higher laccase activity detected in the supernatant of yeast culture producing $\alpha_{\mathrm{OPT} \text { E } \alpha 86 \mathrm{~T} / \mathrm{A} \alpha 87 \mathrm{~N}}-\mathrm{PK} 2$ were due to a higher level of secreted protein (roughly twice the amount produced with $\alpha_{\mathrm{OPT}}$ leader). These results corroborate the contribution of the residues of the spacer region (after Arg85) for the correct processing of the pro-region of $\alpha$-factor preproleader by KEX2 and, consequently, their influence in the overall enzyme secretion process $[66,67$, $72,73]$.

Finally, the "universal" optimised leader, $\alpha_{\mathrm{OPT}}$, exhibited superior secretory potential with other fungal enzymes from different sources: basidiomycete oxidoreductases (versatile peroxidase, aryl-alcohol oxidase and two more laccases) and ascomycete hydrolases (two $\beta$-glucosidases and a sterol esterase). In general, $\alpha_{\mathrm{OPT}}$ leader enhanced enzyme levels from roughly 2 to 20 -fold those obtained with $\alpha_{\text {nat }}$, and also outperformed $\alpha_{9 \mathrm{H} 2}$ for secretion of most enzymes tested, except for two cases (ApL and PcL) where similar values were obtained. Special mention should be given to the production of BGL2, BGL3 and OPE enzymes (96-well plate format), since this work constitutes the first report for functional expression and secretion of these enzymes by $S$. cerevisiae. On the other hand, even though PK2 [42], PcL [32], VP [34] and AAO [74] had been already expressed in the yeast, the production levels were enhanced using the signal peptide optimised here. Moreover, $\alpha_{\mathrm{OPT}}$ leader showed similar behaviour in different media (SEM or EB) and culture conditions (microtiter plates or flask). Even though the differences between $\alpha_{\text {nat }}$ and $\alpha_{\mathrm{OPT}}$ leaders are larger in richer medium during flask production, $\alpha_{\mathrm{OPT}}$ leader maintains its superior secretory capability with ApL and PK2 regardless of the conditions used for yeast growth and laccase production, by contrast to reported medium-dependence of other evolved $\alpha$-factor leaders for laccase expression [45].

\section{Concluding remarks}

We present here an optimised version of the $\alpha$-factor preproleader $\left(\alpha_{\mathrm{OPT}}\right.$ leader) obtained through a dual (bottom-up and top-down) designing strategy of the signal peptide. The systematic scrutiny and combination of mutations selected in previous enzyme-directed evolution campaigns allowed us to disclose the important role that particular regions of the $\alpha$-factor preproleader, such as the pre-region or the spacer region, play in its functionality. The $\alpha_{\mathrm{OPT}}$ leader is able to markedly enhance the secretion of a wide range of fungal enzymes in yeast as compared with the native $\alpha$-factor preproleader (or with other mutated $\alpha$-leaders). Additionally, we propose a guideline to further boost the production yields of a specific recombinant enzyme, through simultaneous randomisation of positions 86th and 87th of the spacer region of $\alpha_{\text {OPT }}$ fused to the target protein, followed by high-throughput screening of the CSM library to select the best mutants.

\section{Materials and methods}

\section{Reagents and strains}

Yeast Transformation Kit, $p$-nitrophenyl butyrate and $p$-nitrophenyl $\beta$-D-galactopyranoside, High Pure Plasmid Isolation Kit, ABTS (2,2'azinobis (3ethylbenzothiazoline- 6 sulphonic acid)), $p$-methoxybenzyl alcohol, and Horseradish peroxidise (HRP) were purchased from Merck. Restriction enzymes NotI and BamHI were obtained from New England Biolabs. Phusion High-Fidelity DNA polymerase was obtained from NEB and QIAquick gel extraction kit from QIAGEN. Zymoprep ${ }^{\mathrm{TM}}$ Yeast Plasmid Miniprep II was purchased from Zymo Research. S. cerevisiae BJ5465 strain was purchased from LGC Promochem (Barcelona, Spain). 


\section{Culture and media}

Minimal Medium (MM) and EB expression medium were synthesised as it is described in Camarero and Co-workers [32]. SEM expression medium was synthesised as it was described in Mateljak and Co-workers [45], without including alcohol. Additionally, $4 \mathrm{mM}$ and $2 \mathrm{mM} \mathrm{CuSO}_{4}$ were added for laccase expression in EB and SEM mediums, respectively. No cofactors were required for the rest of enzymes described in this study.

\section{Enzyme engineering in S. cerevisiae}

I. Agrocybe pediades laccase [46], Pleurotus eryngii laccase (with two mutations to facilitate its functional expression) [46]. PK2 laccase [42], Pycnoporus cinnabarinus laccase [32], $P$. eryngii versatil peroxidase [48], P. eryngii aryl-alcohol oxidase [47], Talaromyces amestolkiae $\beta$-glucosidases $[49,50]$ and Ophiostoma piceae sterol esterase [51] were obtained from our collection of enzymes at CIB. The enzymes' CDS were cloned in the uracil-independent and ampicillin resistant vector $\mathrm{pJRoC} 30$ with the $\alpha$-factor preproleader from Invitrogen by In Vivo Overlap Extension (IVOE) [75]. The primers sense and antisense used are described in the supplementary material. The mutated $\alpha$-factor leaders under study were also cloned in the pJRoC30 vector by IVOE. A first fragment was obtained by PCR with ExtFw sense primer and 87 Final-Rv antisense for $\alpha_{9 \mathrm{H} 2}$ leader or NatFinal-Rv antisense for $\alpha_{\mathrm{A} 9 \mathrm{D}, \mathrm{A} 20 \mathrm{~T}}$ or $\alpha_{\text {nat }}$ leaders, and the second fragment was obtained by PCR with 87FinalFw sense for $\alpha_{9 \mathrm{H} 2}$ or NatFinal-Fw sense for $\alpha_{\mathrm{A} 9 \mathrm{D}, \mathrm{A} 20 \mathrm{~T}}$ or $\alpha_{\text {nat }}$ leaders and ExtRv anti-sense primer (Tables $\mathrm{S} 1$ and S2). The pJRoC30 was linearized with NotI and BamHI restriction enzymes and transformed with the two PCR fragments in S. cerevisiae by IVOE.

II. Bottom-up design of $\alpha$-factor leader. The single mutations R $\alpha 2 \mathrm{~S}, \mathrm{~A} \alpha 9 \mathrm{D}, \mathrm{A} \alpha 20 \mathrm{~T}, \mathrm{~T} \alpha 24 \mathrm{~S}, \mathrm{Q} \alpha 32 \mathrm{H}$, L $\alpha 42 S$, L $\alpha 44 S, F \alpha 48 S, S \alpha 58 G, G \alpha 62 R, D \alpha 83 E$, $\mathrm{E} \alpha 86 \mathrm{G}, \mathrm{A} \alpha 87 \mathrm{~T}$ were incorporated in the sequence of the $\alpha$-factor preproleader from Invitrogen by sitedirected mutagenesis. The same PCR strategy previously described was used adding the suitable sense and anti-sense primers (Table S1). Double, triple and quadruple variants were obtained using a step-by-step addition of mutations.

III. Top-down design of $\alpha$-factor leader. The Ho32Q, $\mathrm{S} \alpha 48 \mathrm{~F}, \mathrm{G} \alpha 58 \mathrm{~S}, \mathrm{R} \alpha 62 \mathrm{G}$ single, double, triple and quadruple reverted mutants from $\alpha_{9 \mathrm{H} 2}$ leader were obtained as described above.

IV. Recombinant library of $\alpha$-factor preproleader mutants fused to PK2 was obtained by adding the mutated sequences $\alpha_{\mathrm{R} 2 \mathrm{~S}} ; \alpha_{\mathrm{A} 9 \mathrm{D}} ; \alpha_{\mathrm{A} 20 \mathrm{~T}} ; \alpha_{\mathrm{T} 24 \mathrm{~S}} ; \alpha_{\mathrm{R} 2 \mathrm{~S}}{ }_{\mathrm{A} 9 \mathrm{D}} ;$ $\alpha_{\mathrm{A} 20 \mathrm{~T}, \mathrm{~T} 24 \mathrm{~S}} ; \alpha_{\mathrm{R} 2 \mathrm{~S}, \mathrm{~A} 9 \mathrm{D},{ }_{\mathrm{A} 20 \mathrm{~T}}, \mathrm{~T} 24 \mathrm{~S}} ;$ and $\alpha_{\mathrm{E} 86 \mathrm{G}, \mathrm{A} 87 \mathrm{~T}}$ in equimolar concentration and in a 2:1 rate respect to BamHI/ NotI linearized pJRoC30 plasmid and transformed $S$. cerevisiae cells using IVOE. Laccase activities from 1600 clones library were analysed by high-throughput screening with $3 \mathrm{mM}$ ABTS and $50 \mathrm{mM}$ Citrate Phosphate $\mathrm{pH}$ 3.0, and double checked by a first rescreening and second rescreening as it is described in Camarero and Co-workers [32].

V. CSM N-Gly58/59 and N-Gly68/69 libraries were obtained by combinatorial saturation mutagenesis over the second and third positions of 57 and 67 $N$-glycosylation sites of the $\alpha$-factor preproleader (specifically of the optimised $\alpha_{\mathrm{A} 9 \mathrm{D}, \mathrm{A} 20 \mathrm{~T}}$ leader). Degenerated sense and anti-sense primers (Arg-X$\mathrm{Ser} / \mathrm{Thr}$ ) were used to replace the amino acid of the second position by all possible amino acid residues (except for Pro) while maintaining the $\mathrm{N}$-glycosylation consensus sequence. CSM 86/87 library was obtained by combinatorial saturation mutagenesis at 86 and 87 positions of the optimised $\alpha_{\mathrm{A} 9 \mathrm{D}, \mathrm{A} 20 \mathrm{~T}}$ leader, using codon degenerated sense and anti-sense oligos (Table. S2) to cover all possible 20 standard amino acid substitutions. The mutated $\alpha$-factor leaders attached to ApL and PK2 laccases cloned in pJRoC30 were used to transformed $S$. cerevisiae cells. Up to 160 clones of each CSM $N$-Gly library (coverage at 95\% of confidence based on GLUE-IT programme [76]) and 1,600 clones of each CSM 86/87 library (coverage at $90 \%$ of confidence) were analysed by high-throughput screening with $3 \mathrm{mM}$ ABTS and $50 \mathrm{mM} \mathrm{CP} \mathrm{pH} 3.0$ and landscapes for the activities of the different clones were obtain for each library respecting the parental activity [32].

\section{Top-down, bottom-up and expression assays of other enzymes}

Assays of expression were analysed in 96-well plates. Ten single colonies of every variant were selected and incubated in $50 \mu \mathrm{l}$ of $\mathrm{MM}$ at $28{ }^{\circ} \mathrm{C}$ and $80 \%$ humidity to prevent evaporation in a humidity shaker (Minitron-INFORS). After $24 \mathrm{~h} 160 \mu \mathrm{l}$ of SEM expression medium were added and incubated for $48 \mathrm{~h}$ at same conditions. Plates were centrifuged, $10 \mathrm{~min}$, at $1000 \mathrm{~g}, 4{ }^{\circ} \mathrm{C}$, and $20 \mu \mathrm{l}$ of supernatant were transferred to a new plate. The replica plate was filled according to the enzyme as follow; laccases with $3 \mathrm{mM}$ ABTS, $50 \mathrm{mM} \mathrm{CP} \mathrm{pH3;} \mathrm{AAO} \mathrm{with} 2 \mathrm{mM} p$-methoxybenzyl alcohol, $100 \mathrm{mM}$ phosphate buffer $\mathrm{pH}$ 6, Horseradish peroxidase (HRP) and $3 \mathrm{mM}$ ABTS; VP with $3 \mathrm{mM}$ ABTS, $100 \mathrm{mM}$ tartrate buffer $\mathrm{pH} \mathrm{3,8} \mathrm{mM} \mathrm{H}_{2} \mathrm{O}_{2}$. After stirring plates were measured in kinetic mode at $418 \mathrm{~nm}$ for ABTS 
$\left(\varepsilon 418=36,000 \mathrm{M}^{-1} \mathrm{~cm}^{-1}\right)$, in SpectraMax M2 plate reader (Molecular Devices) and were normalized against the parental. OPE activity was measured as previously described [77]. BGL activity was determined with $5 \mathrm{mM} p$-nitrophenyl- $\beta$-Dglucopyranoside (pNPG) in $50 \mathrm{mM}$ acetate buffer $\mathrm{pH} 4$. The reaction was stopped after 10 min with sodium carbonate $(2 \% \mathrm{w} / \mathrm{v}$ at the well) and measured at $410 \mathrm{~nm}$.

\section{Enzyme production in flask}

Three single colonies from parental and variants $\alpha$-factor leaders were inoculated in $3 \mathrm{ml} \mathrm{MM}$ at $28^{\circ} \mathrm{C}$ and $200 \mathrm{rpm}$. After $48 \mathrm{~h}$ cultures were diluted to OD600 $=0.3$ and incubated until a final OD $600=1$. Thereafter, $27 \mathrm{ml} \mathrm{EB}$ medium was inoculated with $3 \mathrm{ml}$ of preculture in $250 \mathrm{ml}$ flasks and incubated for $96 \mathrm{~h}$ at $28^{\circ} \mathrm{C}$ and $200 \mathrm{rpm}$. Every $24 \mathrm{~h}$ a $1 \mathrm{ml}$ aliquot was extracted from the cultures to measure their growth (OD600) and laccase activity using $3 \mathrm{mM}$ ABTS, $50 \mathrm{mM} \mathrm{CP} \mathrm{pH} 3$ in kinetic mode at $418 \mathrm{~nm}$ in SpectraMax M2 plate reader (Molecular Devices).

\section{Enzyme purification and specific activity}

PK2 laccase with $\alpha_{\text {OPT }}$ or $\alpha_{\text {OPT E } \alpha 86 T / A \alpha 87 N}$ were grown in $1.21 \mathrm{~EB}$ medium using 11 flasks as described above. After 4 days of incubation, liquid extracts were filtrated (through $0.22 \mu \mathrm{m}$ cut off membrane) and concentrated and ultradiafiltrated using Pellicon tangential filtration membranes (Merck Millipore, Germany) and Amicon stirred cells (Merck Millipore, Germany), both with a $10 \mathrm{kDa}$ cut off. Laccases were purified by FPLC in three anion exchange and an exclusion size chromatography steps: (i) HiPrep QFF $16 / 10$ column in a $100 \mathrm{ml}$ gradient of $0-40 \%$ elution buffer, (ii) HiTrap QFF $5 \mathrm{ml}$ in a $100 \mathrm{ml}$ gradient of 0-40\% elution buffer, (iii) Mono Q HR 5/5 column in a $30 \mathrm{ml}$ gradient of $0-25 \%$ elution buffer, and (iv) Superdex 75. All columns were purchased from GE Healthcare. Enzyme purification was confirmed by SDS-PAGE (12\% acrylamide) stained. For specific activity the final protein concentration was calculated by nanodrop (A280 nm) and laccase activity using $3 \mathrm{mM}$ ABTS, $50 \mathrm{mM} \mathrm{CP}$ pH 3 in kinetic mode at $418 \mathrm{~nm}$ in SpectraMax M2 plate reader (Molecular Devices). Deglycosylation by Endo H (Merck) was performed following the seller's recommendations.

\section{DNA sequencing}

The pJRoC30 plasmid containing enzymes were sequenced by MACROGEN, using the ExtFw sense and ExtRv antisense.

\section{Statistical analysis}

$\mathrm{R}$ was use for the statistical comparison among means of ten replicates of every variant. After an Analysis of Variance, the Tukey's range test was used to determine significant differences from a set of means. Tukey's range test is a multiple comparison test and is applicable when there are more than two means being compared.

Supplementary Information The online version contains supplementary material available at https://doi.org/10.1007/s00018-021-03793-y.

Acknowledgements P.A. acknowledges the Spanish Ministry of Science, Innovation and Universities for his FPU grant and G.M. acknowledges The Tatiana Pérez de Guzmán el Bueno Foundation for his predoctoral Environment grant.

Author contributions PA and GM equally contributed to the work. SC planned the work, PA and GM designed and performed the experiments. FS contributed with some experimental work. PA wrote the paper. SC and GM revised the manuscript critically. All authors read and approved the submitted manuscript version.

Funding This work has been funded by the Spanish project BIO201786559-R, and the WoodZymes project funded by the Bio Based Industries Joint Undertaking (JU) under grant agreement No 792070. The JU receives support from the European Union's Horizon 2020 research and innovation programme and the Bio Based Industries Consortium.

Data availability The data generated or analysed during this study are included in this published article and its supplementary information files.

\section{Declarations}

Conflict of interest The authors declare no conflicts of interest.

Open Access This article is licensed under a Creative Commons Attribution 4.0 International License, which permits use, sharing, adaptation, distribution and reproduction in any medium or format, as long as you give appropriate credit to the original author(s) and the source, provide a link to the Creative Commons licence, and indicate if changes were made. The images or other third party material in this article are included in the article's Creative Commons licence, unless indicated otherwise in a credit line to the material. If material is not included in the article's Creative Commons licence and your intended use is not permitted by statutory regulation or exceeds the permitted use, you will need to obtain permission directly from the copyright holder. To view a copy of this licence, visit http://creativecommons.org/licenses/by/4.0/.

\section{References}

1. Nielsen J (2013) Production of biopharmaceutical proteins by yeast: advances through metabolic engineering. Bioengineered 4:207-211. https://doi.org/10.4161/bioe.22856

2. Huang M, Bao J, Nielsen J (2014) Biopharmaceutical protein production by Saccharomyces cerevisiae : current state and future prospects. Pharm Bioprocess 2:167-182. https://doi.org/10.4155/ pbp. 14.8 
3. Rai M, Padh H (2001) Expression systems for production of heterologous proteins. Curr Sci 80:1121-1128

4. Yin J, Li G, Ren X, Herrler G (2007) Select what you need: a comparative evaluation of the advantages and limitations of frequently used expression systems for foreign genes. J Biotechnol 127:335-347. https://doi.org/10.1016/j.jbiotec.2006.07.012

5. Gerngross TU (2004) Advances in the production of human therapeutic proteins in yeasts and filamentous fungi. Nat Biotechnol 22:1409-1414. https://doi.org/10.1038/nbt1028

6. Ferrer-Miralles N, Domingo-Espín J, Corchero J et al (2009) Microbial factories for recombinant pharmaceuticals. Microb Cell Fact 8:1-8. https://doi.org/10.1186/1475-2859-8-17

7. Cereghino JL, Cregg JM (2000) Heterologous protein expression in the methylotrophic yeast Pichia pastoris. FEMS Microbiol Rev 24:45-66. https://doi.org/10.1016/S0168-6445(99)00029-7

8. Çelik E, Çalik P (2012) Production of recombinant proteins by yeast cells. Biotechnol Adv 30:1108-1118. https://doi. org/10.1016/j.biotechadv.2011.09.011

9. von Heijne G (1990) The signal peptide. J Membr Biol 115:195201. https://doi.org/10.1007/BF01868635

10. Owji H, Nezafat N, Negahdaripour M et al (2018) A comprehensive review of signal peptides: structure, roles, and applications. Eur J Cell Biol 97:422-441. https://doi.org/10.1016/j. ejcb.2018.06.003

11. Ahmad M, Hirz M, Pichler H, Schwab H (2014) Protein expression in Pichia pastoris: recent achievements and perspectives for heterologous protein production. Appl Microbiol Biotechnol 98:5301-5317. https://doi.org/10.1007/s00253-014-5732-5

12. Lin-Cereghino GP, Stark CM, Kim D et al (2013) The effect of $\alpha$-mating factor secretion signal mutations on recombinant protein expression in Pichia pastoris. Gene 519:311-317. https://doi. org/10.1016/j.gene.2013.01.062

13. Fitzgerald I, Glick BS (2014) Secretion of a foreign protein from budding yeasts is enhanced by cotranslational translocation and by suppression of vacuolar targeting. Microb Cell Fact 13:125. https://doi.org/10.1186/s12934-014-0125-0

14. Kjeldsen T, Ludvigsen S, Diers I et al (2002) Engineeringenhanced protein secretory expression in yeast with application to insulin. J Biol Chem 277:18245-18248. https://doi.org/10.1074/ jbc.C200137200

15. Singh A, Chen EY, Lugovoy JM et al (1983) Saccharomyces cerevisiae contains two discrete genes coding for the $\alpha$-factor pheromone. Nucleic Acids Res 11:4049-4063. https://doi.org/10.1093/ nar/11.12.4049

16. Kurjan J, Herskowitz I (1982) Structure of a yeast pheromone gene $(\mathrm{MF} \alpha)$ : a putative $\alpha$-factor precursor contains four tandem copies of mature $\alpha$-factor. Cell 30:933-943. https://doi. org/10.1016/0092-8674(82)90298-7

17. Fuller R (1988) Enzymes required for yeast prohormone processing. Annu Rev Physiol 50:345-362. https://doi.org/10.1146/annur ev.physiol.50.1.345

18. Singh A, Lugovoy JM, Kohr WJ, Perry LJ (1984) Synthesis, secretion and processing of $\alpha$-factor-interferon fusion proteins in yeast. Nucl Acids Res 12:8927-8938. https://doi.org/10.1093/ nar/12.23.8927

19. Caplan S, Green R, Rocco J, Kurjan J (1991) Glyosylation and structure of the yeast MF $\alpha 1 \alpha$-factor precursor is important for efficient transport through the secretory pathway. J Bacteriol 173:627-635. https://doi.org/10.1128/jb.173.2.627-635.1991

20. Rakestraw JA, Sazinsky SL, Piatesi A et al (2009) Directed evolution of a secretory leader for the improved expression of heterologous proteins and full-length antibodies in Saccharomyces cerevisiae. Biotechnol Bioeng 103:1192-1201. https://doi.org/10.1002/ bit. 22338
21. Ng DT, Brown JD, Walter P (1996) Signal sequences specify the targeting route to the endoplasmic reticulum membrane. J Cell Biol 134:269-278. https://doi.org/10.1083/jcb.134.2.269

22. Besada-Lombana PB, Da Silva NA (2019) Engineering the early secretory pathway for increased protein secretion in Saccharomyces cerevisiae. Metab Eng 55:142-151. https://doi.org/10.1016/j. ymben.2019.06.010

23. Waters MG, Evans EA, Blobel G (1988) Prepro- $\alpha$-factor has a cleavable signal sequence. J Biol Chem 263:6209-6214

24. Paetzel M, Karla A, Strynadka NCJ, Dalbey RE (2002) Signal peptidases. Chem Rev 102:4549-4579. https://doi.org/10.1021/ cr010166y

25. Otte S, Barlowe C (2004) Sorting signals can direct receptormediated export of soluble proteins into COPII vesicles. Nat Cell Biol 6:1189-1194. https://doi.org/10.1038/ncb1195

26. Malkus P, Jiang F, Schekman R (2002) Concentrative sorting of secretory cargo proteins into COPII-coated vesicles. J Cell Biol 159:915-921. https://doi.org/10.1083/jcb.200208074

27. Julius D, Brake A, Blair L et al (1984) Isolation of the putative structural gene for the lysine-arginine-cleaving endopeptidase required for processing of yeast prepro- $\alpha$-factor. Cell 37:10751089. https://doi.org/10.1016/0092-8674(84)90442-2

28. Julius D, Blair L, Brake A et al (1983) Yeast $\alpha$ factor is processed from a larger precursor polypeptide: the essential role of a membrane-bound dipeptidyl aminopeptidase. Cell 32:839-852. https ://doi.org/10.1016/0092-8674(83)90070-3

29. Chahal S, Wei P, Moua P et al (2017) Structural characterization of the $\alpha$-mating factor prepro-peptide for secretion of recombinant proteins in Pichia pastoris. Gene 598:50-62. https://doi. org/10.1016/j.gene.2016.10.040

30. Huang M, Wang G, Qin J et al (2018) Engineering the protein secretory pathway of Saccharomyces cerevisiae enables improved protein production. Proc Natl Acad Sci U S A 115:E11025E11032. https://doi.org/10.1073/pnas.1809921115

31. Belden WJ, Barlowe C (2001) Role of Erv29p in collecting soluble secretory proteins into ER-derived transport vesicles. Science 294:1528-1531. https://doi.org/10.1126/science.1065224

32. Camarero S, Pardo I, Cañas AI et al (2012) Engineering platforms for directed evolution of laccase from Pycnoporus cinnabarinus. Appl Environ Microbiol 78:1370-1384. https://doi.org/10.1128/ AEM.07530-11

33. Maté D, García-Burgos C, García-Ruiz E et al (2010) Laboratory evolution of high-redox potential laccases. Chem Biol 17:1030 1041. https://doi.org/10.1016/j.chembiol.2010.07.010

34. Garcia-Ruiz E, Gonzalez-Perez D, Ruiz-Dueñas FJ et al (2012) Directed evolution of a temperature-, peroxide- and alkaline $\mathrm{pH}-$ tolerant versatile peroxidase. Biochem J 441:487-498. https://doi. org/10.1042/BJ20111199

35. Barrero JJ, Casler JC, Valero F et al (2018) An improved secretion signal enhances the secretion of model proteins from Pichia pastoris. Microb Cell Fact 17:161. https://doi.org/10.1186/s1293 4-018-1009-5

36. Martínez ÁT, Speranza M, Ruiz-Dueñas FJ et al (2005) Biodegradation of lignocellulosics: microbial, chemical, and enzymatic aspects of the fungal attack of lignin. Int Microbiol 8:195-204. https://doi.org/10.2436/im.v8i3.9526

37. Baldrian P (2006) Fungal laccases-occurrence and properties. FEMS Microbiol Rev 30:215-242. https://doi.org/10.111 1/j.1574-4976.2005.00010.x

38. Sekretaryova A, Jones SM, Solomon EI (2019) O2 reduction to water by high potential multicopper oxidases: contributions of the T1 copper site potential and the local environment of the trinuclear copper cluster. J Am Chem Soc 141:11304-11314. https:// doi.org/10.1021/jacs.9b05230

39. Morozova OV, Shumakovich GP, Shleev SV, Yaropolov YI (2007) Laccase-mediator systems and their applications: a review. Appl 
Biochem Microbiol 43:523-535. https://doi.org/10.1134/S0003 683807050055

40. Yang J, Li W, Ng TB et al (2017) Laccases: production, expression regulation, and applications in pharmaceutical biodegradation. Front Microbiol 8:832. https://doi.org/10.3389/fmicb.2017.00832

41. Kunamneni A, Camarero S, García-Burgos C et al (2008) Engineering and applications of fungal laccases for organic synthesis. Microb Cell Fact 7:32. https://doi.org/10.1186/1475-2859-7-32

42. De Salas F, Aza P, Gilabert JF et al (2019) Engineering of a fungal laccase to develop a robust, versatile and highly-expressed biocatalyst for sustainable chemistry. Green Chem 21:5374-5385. https://doi.org/10.1039/c9gc02475a

43. Bulter T, Alcalde M, Sieber V et al (2003) Functional expression of a fungal laccase in Saccharomyces cerevisiae by directed evolution. Appl Environ Microbiol 69:5037-5037. https://doi. org/10.1128/aem.69.8.5037.2003

44. Pardo I, Vicente AI, Mate DM et al (2012) Development of chimeric laccases by directed evolution. Biotechnol Bioeng 109:2978-2986. https://doi.org/10.1002/bit.24588

45. Mateljak I, Tron T, Alcalde M (2017) Evolved $\alpha$-factor prepro-leaders for directed laccase evolution in Saccharomyces cerevisiae. Microb Biotechnol 10:1830-1836. https://doi. org/10.1111/1751-7915.12838

46. Aza P, De Salas F, Molpeceres G et al (2021) Protein engineering approaches to enhance fungal laccase production in $S$. cerevisiae. Int J Mol Sci 22:1-19. https://doi.org/10.3390/ijms22031157

47. Carro J, Ferreira P, Rodríguez L et al (2015) 5-Hydroxymethylfurfural conversion by fungal aryl-alcohol oxidase and unspecific peroxygenase. FEBS J 282:3218-3229. https://doi.org/10.1111/ febs. 13177

48. Ruiz-Dueñas FJ, Morales M, Pérez-Boada M et al (2007) Manganese oxidation site in Pleurotus eryngii versatile peroxidase: a site-directed mutagenesis, kinetic, and crystallographic study. Biochemistry 46:66-77. https://doi.org/10.1021/bi061542h

49. Méndez-Líter JA, Gil-Muñoz J, Nieto-Domínguez M et al (2017) A novel, highly efficient $\beta$-glucosidase with a cellulose-binding domain: characterization and properties of native and recombinant proteins. Biotechnol Biofuels 10:256. https://doi.org/10.1186/ s13068-017-0946-2

50. Méndez-Líter JA, De Eugenio LI, Prieto A, Martínez MJ (2018) The $\beta$-glucosidase secreted by Talaromyces amestolkiae under carbon starvation: a versatile catalyst for biofuel production from plant and algal biomass. Biotechnol Biofuels 11:123. https://doi. org/10.1186/s13068-018-1125-9

51. Gutiérrez-Fernández J, Vaquero ME, Prieto A et al (2014) Crystal structures of Ophiostoma piceae sterol esterase: structural insights into activation mechanism and product release. J Struct Biol 187:215-222. https://doi.org/10.1016/j.jsb.2014.07.007

52. Kjeldsen T, Hach M, Balschmidt P et al (1998) Prepro-leaders lacking N-linked glycosylation for secretory expression in the yeast Saccharomyces cerevisiae. Protein Expr Purif 14:309-316. https://doi.org/10.1006/prep.1998.0977

53. Goffeau A, Barrell G, Bussey H et al (1996) Life with 6000 genes. Science 274:546-567. https://doi.org/10.1126/scien ce.274.5287.546

54. Engel SR, Weng S, Binkley G et al (2016) From one to many: expanding the Saccharomyces cerevisiae reference genome panel. Database 2016:baw020. https://doi.org/10.1093/database/baw020

55. Green R, Kramer RA, Shields D (1989) Misplacement of the amino-terminal positive charge in the prepro- $\alpha$-factor signal peptide disrupts membrane translocation in vivo. J Biol Chem 264:2963-2968

56. von Heijne G (1984) Analysis of the distribution of charged residues in the $\mathrm{N}$-terminal region of signal sequences: implications for protein export in prokaryotic and eukaryotic cells. EMBO J
3:2315-2318. https://doi.org/10.1002/j.1460-2075.1984.tb021 32. $\mathrm{x}$

57. Nothwehr SF, Gordon JI (1990) Targeting of proteins into the eukaryotic secretory pathway: Signal peptide structure/function relationships. BioEssays 12:479-484

58. Ast T, Cohen G, Schuldiner M (2013) A network of cytosolic factors targets SRP-independent proteins to the endoplasmic reticulum. Cell 152:1134-1145. https://doi.org/10.1016/j. cell.2013.02.003

59. Song G, Dickins BJA, Demeter J et al (2015) AGAPE (Automated Genome Analysis PipelinE) for pan-genome analysis of Saccharomyces cerevisiae. PLoS ONE 10:e120671. https://doi. org/10.1371/journal.pone.0120671

60. von Heijne G (1984) How signal sequences maintain cleavage specificity. J Mol Biol 173:243-251. https://doi.org/10.1016/00222836(84)90192-X

61. Geukens N, Frederix F, Reekmans G et al (2004) Analysis of type I signal peptidase affinity and specificity for preprotein substrates. Biochem Biophys Res Commun 314:459-467. https://doi. org/10.1016/j.bbrc.2003.12.122

62. Shakin-Eshleman SH, Spitalnik SL, Kasturi L (1996) The amino acid at the $\mathrm{X}$ position of an Asn-X-Ser sequon is an important determinant of N-linked core-glycosylation efficiency. J Biol Chem 271:6363-6366. https://doi.org/10.1074/jbc.271.11.6363

63. Malaby HL, Kobertz WR (2014) The middle X residue influences cotranslational N-Glycosylation consensus site skipping. Biochemistry 53:4884-4893. https://doi.org/10.1021/bi500681p

64. Sidhu RS, Bollon AP (1987) Analysis of $\alpha$-factor secretion signals by fusing with acid phosphatase of yeast. Gene 54:175-184. https ://doi.org/10.1016/0378-1119(87)90485-9

65. Norgaard P (2015) Mating factor alpha pro-peptide variants WO2015/128507A1

66. Kjeldsen T, Brandt J, Andersen AS et al (1996) Corrigendum: a removable spacer peptide in an $\alpha$-factor-leader/insulin precursor fusion protein improves processing and concomitant yield of the insulin precursor in Saccharomyces cerevisiae. Gene 183:107112. https://doi.org/10.1016/S0378-1119(96)00657-9

67. Yang S, Kuang Y, Li H et al (2013) Enhanced production of recombinant secretory proteins in Pichia pastoris by optimizing Kex2 P1' site. PLoS ONE 8:1-11. https://doi.org/10.1371/journ al.pone. 0075347

68. Mate DM, Garcia-Ruiz E, Camarero S et al (2013) Switching from blue to yellow: altering the spectral properties of a high redox potential laccase by directed evolution. Biocatal Biotransformation 31:8-21. https://doi.org/10.3109/10242422.2012.749463

69. Cedillo VB, Plou FJ, Martínez MJ (2012) Recombinant sterol esterase from Ophiostoma piceae: an improved biocatalyst expressed in Pichia pastoris. Microb Cell Fact 11:1-14. https:// doi.org/10.1186/1475-2859-11-73

70. Rockwell NC, Krysan DJ, Komiyama T, Fuller RS (2002) Precursor processing by Kex2/Furin proteases. Chem Rev 102:45254548. https://doi.org/10.1021/cr010168i

71. Bevan A, Brenner C, Fuller RS (1998) Quantitative assessment of enzyme specificity in vivo: $\mathrm{P} 2$ recognition by Kex 2 protease defined in a genetic system. Proc Natl Acad Sci USA 95:1038410389. https://doi.org/10.1073/pnas.95.18.10384

72. Zsebo KM, Lu HS, Fieschko JC et al (1986) Protein secretion from Saccharomyces cerevisiae directed by the prepro-alphafactor leader region. J Biol Chem 261:5858-5865. https://doi. org/10.1016/S0021-9258(17)38462-4

73. Piggott JR, Watson ME, Doel SM et al (1987) The secretion and post translational modification of interferons from Saccharomyces cerevisiae. Curr Genet 12:561-567. https://doi.org/10.1007/ BF00368057

74. Viña-Gonzalez J, Gonzalez-Perez D, Ferreira P et al (2015) Focused directed evolution of aryl-alcohol oxidase in 
Saccharomyces cerevisiae by using chimeric signal peptides. Appl Environ Microbiol 81:6451-6462. https://doi.org/10.1128/ AEM.01966-15

75. Alcalde M, Zumarraga M, Polaina J et al (2006) Combinatorial saturation mutagenesis by in vivo overlap extension for the engineering of fungal laccases. Comb Chem High Throughput Screen 9:719-727. https://doi.org/10.2174/138620706779026079

76. Firth AE, Patrick WM (2008) GLUE-IT and PEDEL-AA: new programmes for analyzing protein diversity in randomized libraries. Nucleic Acids Res 36:281-285. https://doi.org/10.1093/nar/ gkn226
77. Vaquero ME, Barriuso J, Medrano FJ et al (2015) Heterologous expression of a fungal sterol esterase/lipase in different hosts: effect on solubility, glycosylation and production. J Biosci Bioeng 120:637-643. https://doi.org/10.1016/j.jbiosc.2015.04.005

Publisher's Note Springer Nature remains neutral with regard to jurisdictional claims in published maps and institutional affiliations. 